Article

\title{
Formulation, Development, and In Vitro Evaluation of a CD22 Targeted Liposomal System Containing a Non-Cardiotoxic Anthracycline for B Cell Malignancies
}

\author{
Nivesh K. Mittal ${ }^{1, *(1)}$, Bivash Mandal ${ }^{1}$, Pavan Balabathula ${ }^{1,2}$, Saini Setua ${ }^{2}$, \\ Dileep R. Janagam ${ }^{1}$, Leonard Lothstein ${ }^{3}$, Laura A. Thoma ${ }^{2}$ and George C. Wood ${ }^{2}$ \\ 1 Plough Center for Sterile Drug Delivery Solutions, University of Tennessee Health Science Center, \\ Memphis, TN 38163, USA; bmandal@uthsc.edu (B.M.); bpavan18@gmail.com (P.B.); \\ dileep.janagam@gmail.com (D.R.J.) \\ 2 Department of Pharmaceutical Sciences, College of Pharmacy, University of Tennessee Health Science Center, \\ Memphis, TN 38163, USA; ssetua@uthsc.edu (S.S.); 1thoma@uthsc.edu (L.A.T.); gwood@uthsc.edu (G.C.W.) \\ 3 Department of Pathology, College of Medicine, University of Tennessee Health Science Center, \\ Memphis, TN 38163, USA; llothstein@uthsc.edu \\ * Correspondence: nmittal@uthsc.edu; Tel.: +1-901-448-2096
}

Received: 17 March 2018; Accepted: 11 April 2018; Published: 15 April 2018

\begin{abstract}
Doxorubicin cardiotoxicity has led to the development of superior chemotherapeutic agents such as AD 198. However, depletion of healthy neutrophils and thrombocytes from AD 198 therapy must be limited. This can be done by the development of a targeted drug delivery system that delivers AD 198 to the malignant cells. The current research highlights the development and in vitro analysis of targeted liposomes containing AD 198. The best lipids were identified and optimized for physicochemical effects on the liposomal system. Physiochemical characteristics such as size, $\zeta$-potential, and dissolution were also studied. Active targeting to CD22 positive cells was achieved by conjugating anti-CD22 Fab' to the liposomal surface. Size and $\zeta$-potential of the liposomes was between 115 and $145 \mathrm{~nm}$, and -8 to $-15 \mathrm{mV}$. 30\% drug was released over $72 \mathrm{~h}$. Higher cytotoxicity was observed in CD22+ve Daudi cells compared to CD22-ve Jurkat cells. The route of uptake was a clathrin- and caveolin-independent pathway. Intracellular localization of the liposomes was in the endolysosomes. Upon drug release, apoptotic pathways were activated partly by the regulation of apoptotic and oncoproteins such as caspase- 3 and c-myc. It was observed that the CD22 targeted drug delivery system was more potent and specific compared to other untargeted formulations.
\end{abstract}

Keywords: AD 198; B-cell malignancy; liposome; nanoparticle; CD22 targeting

\section{Introduction}

Nanomedicines have seen significant advancements in the past few decades and have been actively pursued as a means of providing alternative drug delivery systems for disease targeted therapies. In 1995, Doxil ${ }^{\circledR}$ established the foundation for the potential of nanomedicines being approved by the United States Food and Drug Administration (FDA) [1]. Since then there has been a rapid increase in research on nanoparticulate drug delivery systems [2]. This has led to the FDA's approval of Abraxane ${ }^{\circledR}$ [3], DaunoXome ${ }^{\circledR}[4]$ and most recently, Marquibo ${ }^{\circledR}[5,6]$. Nanoparticles have provided researchers with the tools to overcome some of the drawbacks of conventional drug delivery systems, most common of which are adverse effects due to non-specific actions of the drug or the drug delivery system $[7,8]$. Specific binding nature of ligands can be exploited to target these types 
of drug carriers to the target tissues or cells [9-14]. Antibodies are one such type of ligand that can be conjugated to nanoparticles to aid in targeted drug delivery. Liposomes are by far one of the most commonly used of the nanoparticulate drug delivery systems, commercially and in clinical trials [15-17]. Liposomes are biodegradable in nature and are versatile in the drug that can be carried as well as the ligands that can be conjugated to their surface for targeted drug delivery [18,19].

Cancer therapy is one field in which researchers have been consistently exploring for breakthroughs using nanotechnology as their primary tool for targeted drug delivery [20,21]. Current medications are still not sufficient to treat the numerous variations of cancers [21], primarily because each variation of cancer needs customized therapies for each patient [20]. Nanotechnology is an adaptable science that can be used to create tailor-made drug delivery systems for specific malignancies.

B cell malignancies are a type of hematological malignancy that have almost 80,000 new cases every year and claim the lives of almost a third of these [22,23]. The standard therapy for B cell malignancies is CHOP [24], of which doxorubicin is an integral part. The treatment of hematological malignancies presents considerable differences from solid cancers in that a large population of the cancer cells are circulating. In a previous review [25] we had discussed the potential of nanoparticles, such as targeted liposomes, being utilized for targeted therapies for B cell cancers. Drug delivery scientists have worked towards the development of a targeted nanoparticulate system for the treatment of $B$ cell cancers $[11,13,14,23,26-31]$. Most of these groups have utilized doxorubicin $[11,14,23,32,33]$ or vincristine $[5,6,34]$ as the drug of choice. Although nanoparticulate systems for both these drugs are already approved by the FDA [1,6], significant enhancements are still needed in view of the adverse effects associated with the non-specific action of the drug delivery system [20] as well as the inherent toxicity of the drug [35]. This has supported the use of novel molecules that would exhibit more desirable properties than currently approved drugs.

Several strategies have been investigated to reduce adverse effects such as the cardiotoxic potential of doxorubicin. One strategy is designing less toxic anthracycline analogues such as epirubicin and idarubicin. However, these analogues only succeeded in delaying cardiotoxic events to higher doses, later stages of therapy or by producing lesser acute cardiotoxicity [36-38]. Valrubicin however, is one anthracycline analogue which lacks cardiotoxicity [39]. N-Benzyladriamycin-14-valerate (AD 198) is another anthracycline that displays no dose-dependent cardiotoxic properties along with an added cardioprotective action from the damage caused by doxorubicin [40-42]. It is a protein kinase C (PKC) activating agent that displays superiority over doxorubicin [41]. It functions by a completely different mechanism of action compared to doxorubicin which has been or is under study by four groups, Cekanova et al., Xie et al., He et al. and Lothstein et al. [40,43-45]. AD 198 does not display any significant organ toxicities and is less myelosuppressive compared to doxorubicin [39]. Myelosuppression, even in reduced forms, is debilitating for the patients undergoing prolonged treatment. To cope with the adverse effects such as neutropenia and thrombocytopenia, we have developed long circulating CD22 targeted liposomes loaded with AD 198 (LCCTLA) and have compared their efficacy with long circulating untargeted liposomal AD 198 (LCLA) and free drug [46]. Consequently, the development of a targeted drug delivery system was expected to impose specificity and considerably moderate adverse effects compared to the other two formulations. Figure 1 gives a schematic representation of the developed LCCTLA drug delivery system. 

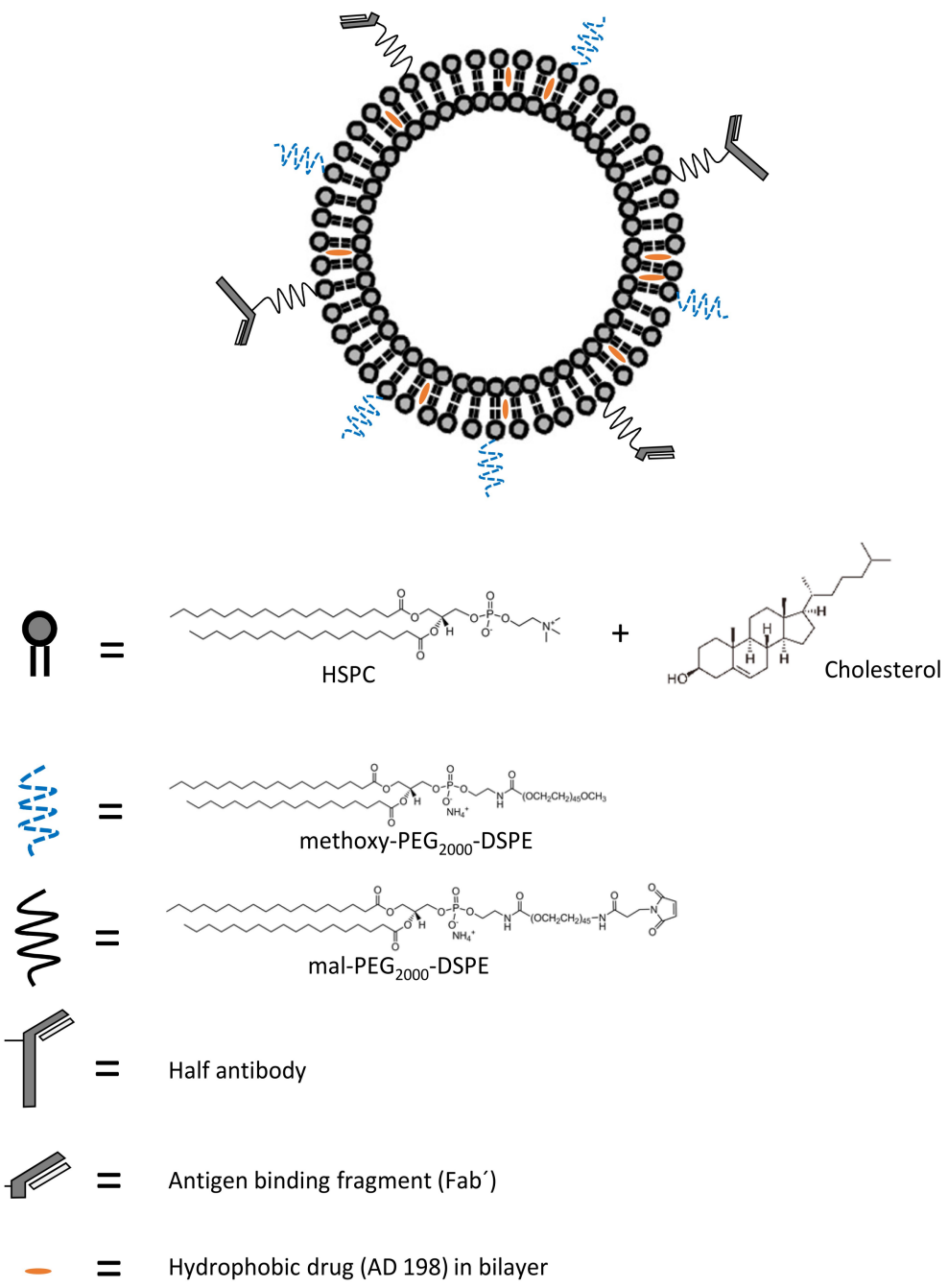

Figure 1. Components of developed long circulating CD22 targeted liposomal AD 198 drug delivery system (HSPC: hydrogenated soy phosphatidylcholine, methoxy-PEG $2000-\mathrm{DSPE}$ : 1,2-distearoylsn-glycero-3-phosphoethanolamine- $N$-[methoxy(polyethylene glycol)-2000], mal-PEG $2000-D S P E: ~ 1,2-$ distearoyl-sn-glycero-3-phosphoethanolamine- $N$-[maleimide(polyethylene glycol)-2000].

\section{Materials and Methods}

\subsection{Materials}

HSPC (hydrogenated soy phosphatidylcholine), EPC (egg phosphatidylcholine), mal-PEG2000DSPE (1,2-distearoyl-sn-glycero-3-phosphoethanolamine- $N$-[maleimide(polyethylene glycol)-2000]), mPEG2000-DSPE (1,2-distearoyl-sn-glycero-3-phosphoethanolamine- $N$-[methoxy(polyethylene glycol)-2000]) and NBD-PC (12-[N-(nitrobenz-2-oxa-1,3-diazol-4-yl) amino] dodecanoyl phosphatidylethanolamine) were purchased from Avanti Polar Lipids, Alabaster, AL, USA, cholesterol, MTT (3-(4, 5-dimethylthiazol-2-yl)-2, 5-diphenyltetrazolium bromide), amiloride, genistein, $\mathrm{M}-\beta-\mathrm{CD}$ (methyl- $\beta$-cyclodextrin) and chlorpromazine were purchased from Sigma-Aldrich Co. LLC, St. Louis, MI, USA, chloroform, methanol, Whatman ${ }^{\circledR}$ Nucleopore track etched polycarbonate membranes, 200 proof ethanol, 10× PBS (phosphate buffered saline) and HPLC (high pressure liquid chromatography) grade water, Slide-A-Lyzer ${ }^{\circledR}$ MINI Dialysis Devices, $3.5 \mathrm{kD}$ MWCO (molecular weight cut off), $0.5 \mathrm{~mL}$ capacity, ammonium hydroxide and $80 \%$ formic acid, immobilized pepsin, Thermo Scientific ${ }^{\mathrm{TM}}$ CL-XPosure ${ }^{\mathrm{TM}}$ Film (X-ray Film), Sepharose CL4B gel filtration gel, anhydrous citric acid, empty PD-10 columns, SDS (sodium dodecyl sulfate), DMF 
(dimethylformamide), DMSO (dimethyl sulfoxide), 80\% acetic acid $1 \mathrm{~N} \mathrm{HCl}$ (hydrochloric acid) and LysoTracker ${ }^{\circledR}$ Deep Red were purchased from Thermo Fisher Scientific, Waltham, MA, USA, ultrapure nitrogen was purchased from Nexair, Memphis, TN, USA, Sephadex G50 pre-filled macro SpinColumns ${ }^{\circledR}$ and empty macro SpinColumns ${ }^{\circledR}$ were purchased from Harvard Apparatus, Holliston, MA, USA, Total Recovery ${ }^{\circledR}$ HPLC vials were purchased from Waters, Milford, MA, USA, anti-CD22 monoclonal antibody (RFB4) was a generous gift from the lab of Ellen Vitetta, University of Texas, Southwestern Medical Center, Dallas, TX, USA, Amicon ${ }^{\circledR}$ Ultra- $0.5 \mathrm{~mL}$ centrifugal filters, Ultrace ${ }^{\circledR} \_100 \mathrm{~K}$ and Ultracel ${ }^{\circledR} — 30 \mathrm{~K}$ were purchased from Millipore, Bellericka, MA, Laemmli buffer and polyacrylamide gels were purchased from Bio-Rad, Hercules, CA, USA, Daudi and Jurkat cells were purchased from ATCC, Manassas, VA, and Vectashield ${ }^{\circledR}$ cell mounting medium with DAPI (4',6-diamidino-2-phenylindole) was purchased from Vector Labs, Burlingame, CA, USA, Iron oxide nanoparticles were purchased from Ocean NanoTech, San Diego CA, USA, antibodies for c-myc \#5605, pAKT \#4058, caspase-3 \#9662 and anti-mouse secondary \#7076 were purchased from Cell Signaling Technologies, Danvers, MA, USA and antibodies for pJNK (sc-571), $\beta$-actin (sc-130065) and anti-rabbit secondary (sc-2357) were purchased from Santa Cruz Biotechnology, Dallas, TX, USA. TEM (transmission electron microscopy) sample preparation materials were generously provided by the Imaging Center at the Neuroscience Institute at UTHSC, Memphis, TN, USA.

\subsection{Preparation and Formulation Optimization of LCLA (Untargeted Long Circulating Liposomal AD 198)}

The liposomes were prepared by the Bangham method [47] followed by extrusion via polycarbonate membranes [12,14,48]. Briefly, the lipids and drug (AD 198 free base) were weighed accurately and dissolved in $3 \mathrm{~mL}$ 9:1 solvent mixture of chloroform:methanol in a round bottom flask. A thin lipid film was formed at the bottom of the flask by evaporating the solvent using a BUCHI Rotavapor $^{\circledR}$. Rotations were maintained at rotation speed no 3 and temperature was maintained at $40{ }^{\circ} \mathrm{C}$ using a BUCHI heating bath. This step was carried out for $1 \mathrm{~h}$ following which the vacuum was released, and the water bath heated to $65^{\circ} \mathrm{C}$. Simultaneously, $1 \times$ PBS was prepared from the $10 \times$ PBS and added to the thin lipid film for hydration. Rotations were maintained at the number 3 setting. Hydration was carried out for $1 \mathrm{~h}$ which gave MLVs (multi-lamellar vesicles). The MLVs were extruded through polycarbonate filters in two steps to give SUVs (small unilamellar vesicles). Extrusion was carried out using LIPEX ${ }^{\circledR}$ Extruders purchased from Northern Lipids, Burnaby, BC, Canada, connected to a high pressure ultrapure nitrogen tank. In the first step of extrusion, polycarbonate membranes of two sizes, $100 \mathrm{~nm}$ (nanometers) and $200 \mathrm{~nm}$, were stacked and the drug loaded liposomes extruded only once using $450 \mathrm{psi}$ pressure. In the second step, the resulting liposomes were extruded three times via $80 \mathrm{~nm}$ and $100 \mathrm{~nm}$ stacked membranes again using 450 psi pressure. Since there was some loss of volume during the rehydration and extrusion process, the final volume was made up to $3 \mathrm{~mL}$ with $1 \times$ PBS. The size and $\zeta$-potential (zeta potential) of the final liposomes was measured using a Malvern Zetasizer Nano ZS.

\subsection{Removal of Un-Encapsulated AD 198}

The unencapsulated drug was removed using Sephadex-G50 prefilled macro-column $[49,50]$. Briefly, the powdered G50 gel was rehydrated using $1 \times$ PBS for $15 \mathrm{~min}$ and centrifuged using a Thermo Scientific IEC CL31R centrifuge at $4{ }^{\circ} \mathrm{C}$ for $4 \mathrm{~min}$ at $1500 \mathrm{rpm}$. The resulting gel was washed three times using $150 \mu \mathrm{L}$ of blank liposomes containing no AD 198, under the same centrifugation conditions as mentioned above. This was to block any non-specific retention of drug loaded liposomes in the column. Then $150 \mu \mathrm{L}$ of the AD 198 loaded liposomes were passed through the treated column. The final eluate was reconstituted to $150 \mu \mathrm{L}$.

\subsection{Analysis of Liposomal Encapsulated Drug Content}

Encapsulated AD 198 content in the liposomes was calculated using a Waters Alliance e2695 HPLC coupled to a Waters 2998 UV Photodiode Array Detector. Samples were prepared at a dilution 
factor of 20. Briefly, $50 \mu \mathrm{L}$ of the purified liposomes were dissolved in $950 \mu \mathrm{L}$ of 1:1 methanol:ethanol. Samples were briefly vortexed to give a clear solution and $300 \mu \mathrm{L}$ transferred to Waters total recovery HPLC vials. These vials were loaded into the autosampler of the HPLC separations module. Conditions for HPLC analysis were adapted from previously optimized methods [51]. The column used for separation was Waters Nova-Pak ${ }^{\circledR} \mathrm{C} 184 \mu \mathrm{m}, 3.9 \times 150 \mathrm{~mm}$ and was maintained at $30{ }^{\circ} \mathrm{C}$ throughout the separation process. The mobile phase was a 70:30 acetonitrile:pH 4.0 ammonium formate buffer. The ammonium formate buffer was prepared by adding $3.85 \mathrm{~mL}$ of ammonium hydroxide to $950 \mathrm{~mL}$ of HPLC grade water. The $\mathrm{pH}$ was adjusted to 4.0 using $80 \%$ formic acid and the volume was made up to $1 \mathrm{~L}$. The flow rate for the mobile phase was maintained at $1.2 \mathrm{~mL} / \mathrm{min}$, the injection volume was $20 \mu \mathrm{L}$ and the run time for each injection was $7 \mathrm{~min}$. AD 198 eluted between 3 and $4 \mathrm{~min}$ and was detected at a wavelength $(\lambda)$ of $254 \mathrm{~nm}$.

\subsection{Determination of Phospholipid Concentration}

To calculate the amount of HSPC retained in the final formulation of LCLA, total phospholipids were estimated using a procedure adapted from Stewart et al. [52]. $2.703 \mathrm{~g}$ (grams) ferric chloride hexahydrate and $3.04 \mathrm{~g}$ ammonium thiocyanate was dissolved in $100 \mathrm{~mL}$ distilled water and mixed to give ferrithiocyanate reagent. To determine the concentration of HSPC in the LCLA dispersion, an HSPC standard curve was made ranging from 10 to $60 \mu \mathrm{g} / \mathrm{mL}$. Analysis of these standards was done as follows. A mixture of $2 \mathrm{~mL}$ chloroform, $2 \mathrm{~mL}$ ferrithiocyanate reagent and $100 \mu \mathrm{L}$ of the standard solution was made for each standard and vortexed vigorously for exactly one min each. The mixture was allowed to settle and the lower layer containing chloroform was aspirated carefully and transferred to a $1 \mathrm{~mL}$ quartz cuvette. The absorbance for each standard was measured at $\lambda 488$ against a chloroform blank. Samples of LCLA were prepared in the same method and the absorbance measured. Absorbance of the standard vs. HSPC concentration was plotted for each standard concentration and the unknown amount of HSPC in the LCLA sample was determined.

\subsection{LCLA AD 198 Release Study}

Drug release in $1 \times$ PBS at $\mathrm{pH} 7.4$ and $37{ }^{\circ} \mathrm{C}$ was tested for the LCLA's as described by Zhang et al. [53]. Briefly, $100 \mu \mathrm{L}$ of the LCLA's were placed in Slide-A-Lyzer ${ }^{\circledR}$ MINI Dialysis Devices, 3.5 K MWCO, $0.5 \mathrm{~mL}$ capacity [54,55]. 5 time points were tested; 6, 12, 24, 48 and 72 h. Each sample was tested in triplicates. The sample loaded dialysis devices were loaded into floats introduced into a $3000 \mathrm{~mL}$ beaker containing $3000 \mathrm{~mL}$ of $1 \times$ PBS preheated to $37^{\circ} \mathrm{C}$ and dissolution started. Samples were taken out at the pre-determined time points and the drug content measured by HPLC as stated earlier.

\subsection{Fab' (Antigen Binding Fragment) Generation from Whole Anti-CD22 Antibody}

The anti-CD22 whole antibody was first purified by passing through a G50 prefilled macro column. The Fc (constant fragment) region was first digested using immobilized pepsin. Briefly, the immobilized pepsin was first separated from the vehicle by loading the immobilized pepsin suspension into an empty macro column and centrifuging it for $2 \mathrm{~min}$ at $5000 \mathrm{~g}$ and $4{ }^{\circ} \mathrm{C}$. The purified anti-CD22 monoclonal antibody was then incubated with the immobilized pepsin at $\mathrm{pH} 3.0,37^{\circ} \mathrm{C}$ for $6 \mathrm{~h}$. pH 3.0 was adjusted using 1M citric acid solution. After the given time, the antibody was collected by centrifuging the immobilized pepsin and antibody digest in an empty macro spin column at $5000 \mathrm{~g}$ for $2 \mathrm{~min}$ at $4{ }^{\circ} \mathrm{C}$. The collected antibody digest was then incubated with $10 \mu \mathrm{l}$ of $5 \mathrm{mM}$ TCEP (tris(2-carboxyethyl)phosphine) at room temperature (RT) for $1 \mathrm{~h}$. This gave $2 \mathrm{Fab}^{\prime}$ fragments from each molecule of antibody. The resulting digest mix was purified by filtration using two filters $100 \mathrm{kD}$ and $30 \mathrm{kD}$ MWCO and the appropriate fraction containing the $50 \mathrm{kD} \mathrm{Fab}$ ' was collected and used for conjugation. A schematic or this reaction is given in Figure $2 \mathrm{~A}$. 
(A)
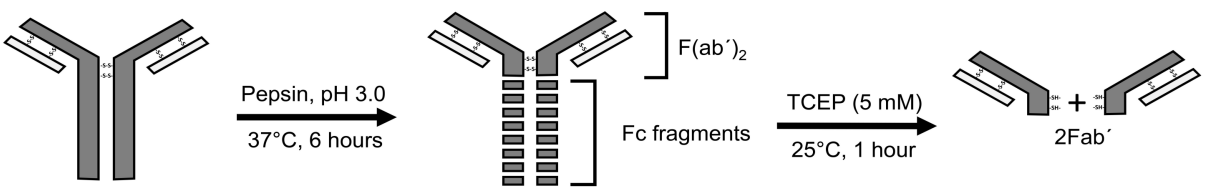

(B)

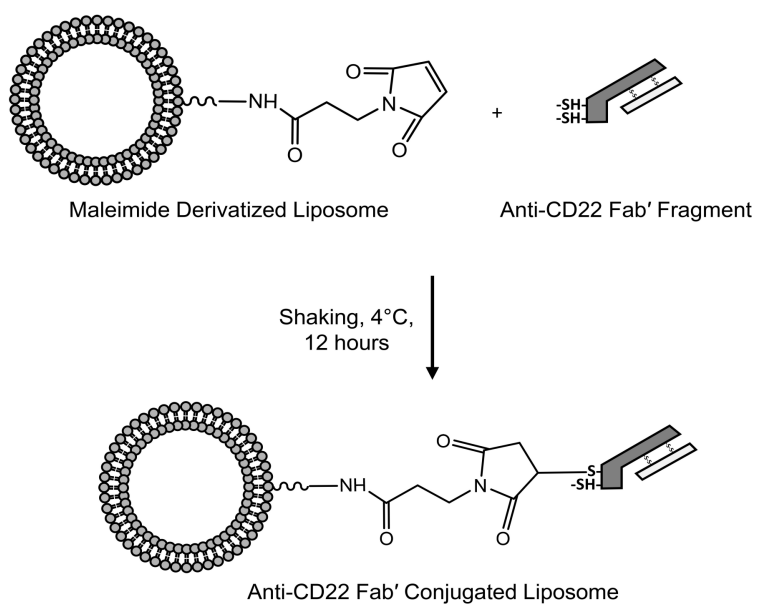

Figure 2. (A) Schematic for generation of anti-CD22 Fab' fragments; and (B) Conjugation of anti-CD22 Fab' to maleimide derivatized LCLA (untargeted long circulating liposomal AD 198).

\subsection{Conjugation of Fab' to Liposomes to Give Long Circulating CD22 Targeted Liposomal AD 198 (LCCTLA)}

For conjugation with antibody, liposomes were prepared by the same method as mentioned above, only 50\% of m-DSPE-PEG2000 was replaced with mal-PEG2000-DSPE to serve as an anchor for the antibody. $100 \mu \mathrm{L}$ of the Fab' was incubated with an equal volume of the maleimide derivatized liposomes at $4{ }^{\circ} \mathrm{C}$ for $12-15 \mathrm{~h}$. Following incubation, unconjugated antibody fragments were removed by gel filtration chromatography using Sepharose CL4B gel. Briefly, the 70\% gel slurry in ethanol was filled in an empty PD-10 column and centrifuged at $1000 \mathrm{~g}$ for $150 \mathrm{~s}$ at $4{ }^{\circ} \mathrm{C}$ to remove the ethanol. Three $1 \times$ PBS washes followed the removal of ethanol. The column was the saturated with placebo liposomes in three separate runs and then the $200 \mu \mathrm{L}$ of targeted liposomes were passed through the column. The final reaction for the conjugation between the maleimide derivatized liposomes is depicted in Figure 2B. The resulting solution was analyzed for proof of conjugation by western blotting.

\subsection{Verification of Conjugation}

Conjugation of the $50 \mathrm{kD} \mathrm{Fab}$ ' fragment to the liposomes was verified by western blotting as done by Oliveira et al. [56]. Briefly, 4 samples were studied: the targeted liposomes, the fraction higher than $100 \mathrm{kD}$, the fraction below $50 \mathrm{kD}$ and the whole antibody were quantified for total protein by the BCA assay and $20 \mu \mathrm{L}(10 \mu \mathrm{L}$ sample and $10 \mu \mathrm{L}$ Laemmli buffer) of an equal concentration sample of protein (250 ng) were loaded into a 4-15\% polyacrylamide gel. Samples were run at $100 \mathrm{~V}$ for approximately one hour (until the Laemmli dye reached the end of the gel). The protein bands were then transferred from the gel onto a PVDF (polyvinylidene fluoride) membrane. The membrane was probed with a mouse secondary antibody and the blot was developed on an X-ray film.

\subsection{Calculation of Number of Antibody Molecules per Liposome}

The number of anchors (maleimide groups) and the number of antibody molecules per liposome were calculated by first calculating the number of liposomes as previously discussed. Then number of antibody molecules and maleimide were calculated in one mL of the LCCTLA by using Avogadro's number and substituting the values in Equations (1) to (7). 


\subsection{Cellular Uptake of LCLA and LCCTLA by Flow Cytometry}

To determine and compare cellular uptake in CD22 ${ }^{+}$Daudi and CD22- Jurkat cells CD22 targeted liposomes were prepared by the same method as specified previously only 0.125 mole $\%$ of the HSPC was substituted with an equal mole percent of NBD-PC for fluorescence imaging. Six time points were tested ranging from $5 \mathrm{~min}$ to $4 \mathrm{~h}$ [57]. $10 \mathrm{ml}$ each of Daudi and Jurkat cells at a cell density of $7 \times 10^{5}$ cells $/ \mathrm{mL}$ were grown in T25 flasks for each time point. At each time point, both cell types were treated with two types of $1 \mu \mathrm{M}$ AD 198 formulations, LCLA and LCCTLA separately. At the end of each time point the cells were centrifuged at $4{ }^{\circ} \mathrm{C}$ and $100 \mathrm{~g}$ for $4 \mathrm{~min}$. The pellet obtained was washed with $1 \times$ PBS thrice and the final cell pellet was re-suspended in $1 \mathrm{~mL}$ of $1 \times \mathrm{PBS}$ and tested for fluorescence intensity for NBD-PC per 10,000 cells using the BD Accuri ${ }^{\mathrm{TM}} \mathrm{C} 6$ flow cytometer (BD Biosciences, San Jose, CA, USA).

\subsection{Evaluation of LCCTLA Cytotoxicity}

To determine cellular cytotoxicity, the MTT assay was used [58]. Briefly, Daudi and Jurkat cells were grown to the required cell density. The assay was set up in 96 well plates. Three different formulations of AD 198 were tested; LCCTLA, LCLA and free AD 198. Free AD 198 was prepared in DMSO such that the final concentration of DMSO was less than $3 \%$ in any treatment well. Two time points were prepared for each treatment, $24 \mathrm{~h}$ and $48 \mathrm{~h}$. For the 24 -h treatment 17,500 cells per well were plated and for the 48 -h treatment 8750 cells per well were plated. Treatment was done for 10 concentrations of each of the three AD 198 formulations ranging from $0.01 \mu \mathrm{M}$ to $3 \mu \mathrm{M}$ and the control was cells with no drug treatment. These plates were incubated at $37^{\circ} \mathrm{C}$ and $5 \% \mathrm{CO}_{2}$ for the study time period. At the end of the study time ( 24 or $48 \mathrm{~h}) 15 \mu \mathrm{L}$ of $5 \mathrm{mg} / \mathrm{mL}$ concentration of MTT dye was added to each well of study and incubated under the same conditions mentioned above for 4 more $\mathrm{h}$ at $37^{\circ} \mathrm{C}$. Following the 4 -h incubation the insoluble formazan dye formed as a result of the reaction was dissolved in $100 \mu \mathrm{L}$ of solubilization buffer $(20 \%$ SDS in $50 \%$ DMF, $0.5 \%$ of $80 \%$ acetic acid and $0.4 \% 1 \mathrm{~N} \mathrm{HCl}$ ) and incubated for $3 \mathrm{~h}$ at $37^{\circ} \mathrm{C}$. After incubation absorbance was read at $\lambda 570 \mathrm{~nm}$ using the SpectraMax M2e ${ }^{\circledR}$ microplate reader (Molecular Devices, San Jose, CA, USA).

\subsection{Energy Dependent or Independent Pathway for LCCTLA Internalization}

To confirm that the mechanism of uptake of LCCTLA particles into Daudi cells was by receptor-mediated endocytosis cellular association studies were performed [56]. Briefly, $10 \mathrm{~mL}$ of Daudi cells at a cell density of $7 \times 10^{5}$ cells $/ \mathrm{mL}$ were grown in two separate T25 flasks. One was pre-cooled to $4{ }^{\circ} \mathrm{C}$ and then treated with $1 \mu \mathrm{M}$ fluorescent LCCTLA for one hour and the other was treated with $1 \mu \mathrm{M}$ fluorescent LCCTLA at $37^{\circ} \mathrm{C}$ for one hour. At the end of the time point, the cells were centrifuged at $4{ }^{\circ} \mathrm{C}$ and $100 \mathrm{~g}$ for $4 \mathrm{~min}$. The pellet obtained was washed with $1 \times$ PBS thrice and the final cell pellet was re-suspended in $1 \mathrm{~mL}$ of $1 \times \mathrm{PBS}$ and tested for fluorescence intensity for NBD-PC per 10,000 cells using the BD Accuri ${ }^{\mathrm{TM}}$ C6 Flow cytometer.

\subsection{Route of Uptake of LCCTLA into Daudi Cells}

To determine the mechanism of entry of LCCTLA into the Daudi cells, various inhibitors were used to block specific pathways and then the uptake analyzed as done in the determination of CD22 targeted liposomal drug uptake in cells by flow cytometry. As per Douglas et al. [59] four specific inhibitors were used; amiloride for micropinocytosis, genistein or $\mathrm{M}-\beta-\mathrm{CD}$ for caveolae and related structures mediated endocytosis and chlorpromazine for clathrin-mediated endocytosis. $10 \mathrm{~mL}$ Daudi cells at a concentration of $7 \times 10^{5}$ cells $/ \mathrm{mL}$ were incubated with the inhibitors for one hour at the following specific concentrations; amiloride $10 \mu \mathrm{M}$, genistein $0.2 \mu \mathrm{M}$ and chlorpromazine $10 \mu \mathrm{g} / \mathrm{mL}$. Following this the inhibitor treated cells were treated with $1 \mu \mathrm{M}$ fluorescent CD22 targeted liposomal AD 198 and incubated for $1 \mathrm{~h}$ at $37^{\circ} \mathrm{C}$. At the end of the treatment the cells were processed in the same method as for the determination of LCCTLA uptake in Daudi cells by flow cytometry. 


\subsection{Intracellular Trafficking of LCCTLA by TEM}

\subsubsection{Preparation and Treatment of Daudi Cells}

To view the intracellular localization of LCCTLA in the Daudi cells [60,61], $15 \mathrm{~nm}$ sized magnetic iron oxide nanoparticles in water (with carboxylic acid functional group) were processed into the liposomes [62]. Briefly, $1 \% w / w$ iron oxide nanoparticles were added to the $1 \times$ PBS that was used to rehydrate the dried lipid film. The MLV's thus obtained were sonicated for $5 \mathrm{~s}$ with 5 min intervals (extrusion was initially tried as the size reduction technique, however the liposomes failed to extrude). During the sonication and the interval, the liposomal suspension was kept in ice. The sonication was repeated three times to give magnetic LCLA (MLCLA). The anti-CD22 Fab' was conjugated as specified previously to give MLCCTLA (magnetic LCCTLA). $10 \mathrm{~mL}$ Daudi cells at a density of $7 \times 10^{5}$ cells $/ \mathrm{mL}$ were treated with $1 \mu \mathrm{M}$ of the MLCCTLA for $4 \mathrm{~h}$. After treatment, the cells were centrifuged at $100 \mathrm{~g}$ for $5 \mathrm{~min}$ at $4{ }^{\circ} \mathrm{C}$. The pellet was washed with ice cold $1 \times$ PBS thrice and suspended in $1 \mathrm{~mL} 2.5 \%$ glutaraldehyde in $1 \times$ PBS.

\subsubsection{TEM Sample Preparation}

Once the cells were fixed in $2.5 \%$ glutaraldehyde overnight they were spun down at $100 \mathrm{~g}$ for 5 min and washed with $10 \times$ PBS thrice for 20 min each. Then the cells were stained with a $4 \%$ osmium tetroxide in PBS solution for $1 \mathrm{~h}$ at RT and excess stain washed off using 10× PBS thrice for $20 \mathrm{~min}$ each. The cell sample was then dehydrated in an ethanol series gradually increasing from $50 \%$ ethanol to $100 \%$ ethanol in four steps. Each dehydration cycle was done once for $10 \mathrm{~min}$ and the $100 \%$ ethanol thrice. The cells were then infiltrated with $50 \%$ Spurr's resin in ethanol under rotation overnight. Infiltration was continued with 100\% Spurr's resin the next day thrice for $2 \mathrm{~h}$ periods. With the $100 \%$ Spurr's resin, the centrifugation was done at $800 \mathrm{~g}$ for $20 \mathrm{~min}$. The cells were then embedded in fresh Spurr's resin in a mold and cured at $65{ }^{\circ} \mathrm{C}$ for $48 \mathrm{~h}$. Once the resin hardened the sample block was placed in an ultramicrotome and approximately $80 \mathrm{~nm}$ sections cut using a diamond knife. Chloroform was used to smoothen the sections. The sections were loaded onto copper grids and stained with uranyl acetate and lead citrate to increase contrast and electron density. The grids were then inserted into the TEM for viewing. The TEM used was the JEOL 2000EX with a high resolution digital camera and monitor (JEOL, Peabody, MA, USA).

\subsection{Intracellular Trafficking of LCCTLA by CLSM}

To confirm that the intracellular vesicles the magnetic liposomes were observed in were endolysosomes, cells were stained with endolysosome specific dye [63-65]. Briefly, $10 \mathrm{~mL}$ Daudi cells were cultured to a cell density of $7 \times 10^{5}$ cells $/ \mathrm{mL}$ and treated with $10 \mu \mathrm{L}$ of placebo fluorescent CD22 targeted liposomes (prepared by substituting 0.125 mole $\%$ of HSPC with an equal mole $\%$ of NBD-PC, and not loading any drug) for $1 \mathrm{~h}$. During the final 5 min of treatment, $50 \mathrm{nM}$ LysoTracker ${ }^{\circledR}$ Deep Red was added to the treated cell culture. The media was then removed by centrifugation and the cell pellet thus obtained was washed 3 times using $1 \times$ PBS. The final cell pellet was suspended in a single drop of Vectashield ${ }^{\circledR}$ cell mounting medium with DAPI. This final cell suspension was mounted onto a microscope slide and covered by a Fisherbrand number 1 coverslip. The slide was allowed to dry in a fume hood for approximately $30 \mathrm{~min}$ and the edges were sealed using a transparent nail polish. The nail polish was also allowed to dry in a fume hood for another $30 \mathrm{~min}$ after which the slide was viewed under a Nikon Eclipse E800 confocal scanning laser microscope (Nikon Instruments, Melville, NY, USA). The lasers were set at the wavelength for NBD-PC, LysoTracker ${ }^{\circledR}$ Deep Red and DAPI and images were obtained.

\subsection{Effect of LCCTLA on Cell Cycle Regulatory Molecules by Western Blot}

To study the efficacy of the drug delivery system on induction of apoptosis in the cancer cells, the cells were treated with the LCCTLA and the expression of 4 proteins was monitored, Caspase 3 , 
c-myc, p-JNK, pAKT. $\beta$-actin was used as a control to signify equal loading. The process [66] has been briefly outlined below.

\subsubsection{Sample preparation}

$10 \mathrm{~mL}$ of Daudi cells at a density of $7 \times 10^{5}$ cells $/ \mathrm{mL}$ were treated with $1 \mu \mathrm{M}$ of LCCTLA at three separate time points, 2, 4 and $6 \mathrm{~h}$. The control was the same density and volume of cells but without any drug treatment. At the end of the treatment, cells were centrifuged in a Thermo Scientific Sorvall Legend X1 centrifuge (Thermo Fisher Scientific, Waltham, MA, USA) at $100 \mathrm{~g}$ for $4 \mathrm{~min}$ at $4{ }^{\circ} \mathrm{C}$. The pellet obtained was washed with $1 \times$ PBS thrice and then suspended in $70 \mu \mathrm{L}$ whole cell lysis buffer [Tris $\mathrm{HCl} 50 \mathrm{mM}, \mathrm{NaCl}$ (sodium chloride) $150 \mathrm{mM}$, Triton X-100 1\%, SDS 0.1\%, EDTA (ethylene diamine tetra acetic acid) $5 \mathrm{mM}, \mathrm{Na}_{2} \mathrm{HPO}_{4}$ (disodium phosphate) $30 \mathrm{mM}, \mathrm{NaF}$ (sodium fluoride) $50 \mathrm{mM}, \mathrm{NaVO}_{4}$ (sodium orthovandate) $0.5 \mathrm{mM}$, PMSF (phenylmethylsulfonylfluoride) $2 \mathrm{mM}$ and protease inhibitor] at $1 \mu \mathrm{L} / 10^{6}$ cells. This cell suspension was sonicated using a Virtis Virsonic ${ }^{\circledR}$ Ultrasonic Cell Disrupter. The samples were sonicated thrice for $5 \mathrm{~s}$ each with $5 \mathrm{~min}$ intervals. During the intervals, the cell debris suspension was placed on ice. The cell debris suspension was then centrifuged at $1000 \mathrm{rpm}$ at $4{ }^{\circ} \mathrm{C}$ for $10 \mathrm{~min}$ and the supernatant collected. The pellet obtained was discarded.

\subsubsection{Polyacrylamide Gel Electrophoresis (PAGE)}

The protein content in the supernatant collected was quantified using the microplate BCA (bicinchoninic acid) protein assay. A volume of protein was calculated such that all samples had an equal concentration of protein. These whole cell protein samples were then mixed with an equal volume of $2 \times$ Laemmli sample buffer and boiled for $5 \mathrm{~min}$. Samples were then cooled to RT for $3 \mathrm{~min}$ and loaded onto a $4-15 \%$ polyacrylamide gel of $50 \mu \mathrm{L}$ well capacity. The buffer reservoir was filled up with electrode running buffer to the given mark. The electrodes were connected to a Bio-Rad power pack and samples were electrophoresed at $100 \mathrm{~V}$ for approximately one hour (until the Laemmli sample dye reached near the bottom of the gel).

\subsubsection{Blotting}

The gel was then loaded onto a transfer cassette to transfer the protein bands onto a PVDF membrane. The sized membrane was first soaked in 100\% methanol followed by transfer buffer. It was then placed over the gel in the cassette and the transfer apparatus set up. A stir bar was placed at the bottom of the buffer reservoir along with a freezer pack. Transfer buffer was then poured into the reservoir to a level such that the freezer pack was fully submerged and covered the cassette completely. The electrodes were connected to a Bio-Rad power pack and the transfer was done at $100 \mathrm{~V}$ for one hour.

\subsubsection{Primary and Secondary Antibody Probing}

Once the bands were transferred to the membrane, the membrane was blocked using either $5 \%$ powdered milk or $5 \%$ BSA (bovine serum albumin) in TBST (Tris-buffered saline and Tween ${ }^{\circledR} 20$ ). The blocking was done at RT for $1 \mathrm{~h}$ on a shaker. After the blocking was complete, excess milk or BSA was washed off the membrane with TBST (a quick wash) and the primary antibody for a specific protein was added at a dilution of 1:1000 (only $\beta$-actin 1:40,000) in TBST. The blot was incubated with the primary antibody for $12-15 \mathrm{~h}$ at $4{ }^{\circ} \mathrm{C}$ on a rocker. At the end of the incubation period, the excess primary antibody was washed off the membrane using TBST. The wash was done thrice for 5 min each. Then, the membrane was incubated with secondary antibody specific for the particular antibody used (anti-rabbit for c-myc, pJNK, pAKT and caspase-3 and anti-mouse for $\beta$-actin) at a dilution of 1:25,000 for $1 \mathrm{~h}$ at RT. The excess secondary antibody was then washed off the membrane using TBST thrice for 15 min each. 


\subsubsection{Analysis}

Once the secondary antibody was probed onto the membrane, the substrate (hydrogen peroxide + luminol) was added and briefly incubated for 1-2 min. The membrane was then loaded onto an X-ray film cassette and covered with a fresh X-ray film. This film was then developed, and the results recorded.

\subsubsection{Membrane Stripping}

The membrane was reused for probing another protein with another antibody. For this, the previous antibody was removed by a process called stripping and was done by a stripping buffer. The membrane already bound with the primary and secondary antibody was incubated with the stripping buffer for $5 \mathrm{~min}$ at $45^{\circ} \mathrm{C}$ following which it was washed with TBST and was reused for probing the next protein.

\subsection{Statistical Methodology}

All work was performed in triplicates $(n=3)$. Data are expressed as mean \pm standard deviation (SD). Student's t-test was used for data analysis; $p$-values $\leq 0.05$ were considered statistically significant.

\section{Results}

\subsection{This Section Effect of Lipid Composition in the Bilayer}

EPC and HSPC were studied for their effects on the physico-chemical properties of the liposomes such as liposomal encapsulation of AD 198, size and $\zeta$-potential. Both lipids are derived from natural sources and are biodegradable. However, HSPC and EPC differ in their composition such that EPC is a crude mixture of saturated and unsaturated lipids of varying chain lengths, whereas HSPC is primarily composed of saturated lipids of a fixed chain length. The effect that this has on the lipid bilayer is that the longer chain length lipids in EPC increase the thickness of the bilayer (not the size of the liposome) [67]. The more saturated a lipid is, the higher is its transition temperature, thus imparting lesser fluidity and possibly increased stability [67]. A variable length between the two tail group chains also reduces the order of packing in the liposomal bilayer. Liposomes with saturated lipids such as HSPC also have higher circulation half-lives compared to liposomes with unsaturated lipids such as EPC [68,69].

Studies were performed using HSPC and EPC at various ratios to optimize the physico-chemical properties of LCLA. Figure 3A shows EPC and HSPC formulations studied in various ratios for their effect on AD 198 encapsulation, liposomal size, and $\zeta$-potential. It was observed that the size of the liposomes was not related to the lipid composition in any definitive manner. One hundred percent HSPC gave the smallest liposomal size. Liposomal AD 198 concentration was also not associated with the lipid composition in a significant manner with 100\% HSPC giving highest AD 198 encapsulation. Dependence of $\zeta$-potential on the lipid composition however displayed a trend compared to size and drug encapsulation. As the percentage of HSPC was increased, $\zeta$-potential became more electronegative with an average value of $-19.3 \mathrm{mV}$ at $100 \%$ HSPC concentration. Although the other formulations containing some percentage of EPC produced liposomes of size, $\zeta$-potential and AD 198 encapsulation comparable to the formulation with 100\% HSPC, the latter was selected as the formulation of choice this point forward due to the difficulty of working with EPC which can be attributable to its lesser stable nature which makes for a very hygroscopic powder and lesser stable formulations due to the unsaturation in its structure. 

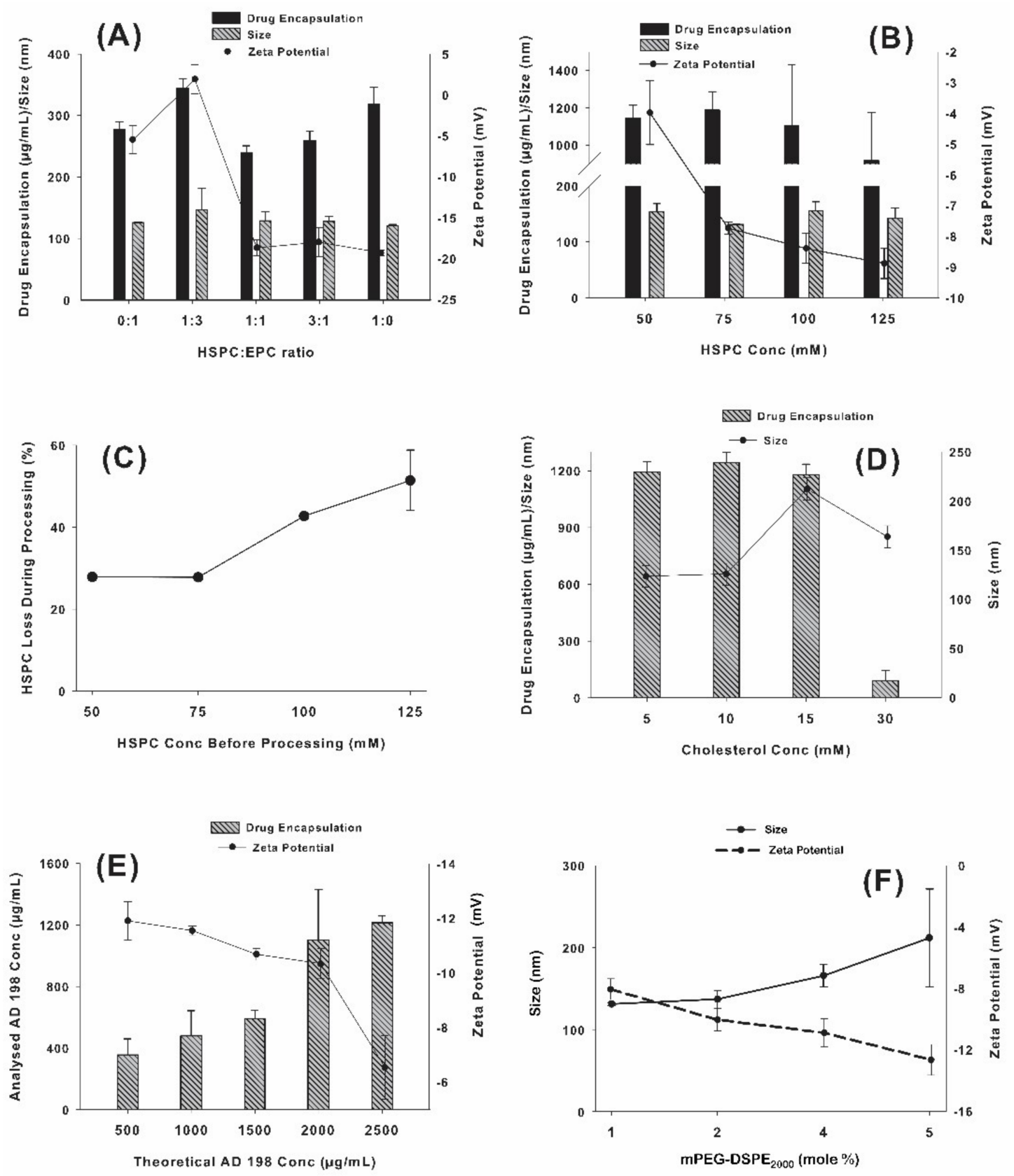

Figure 3. (A) Effect of lipid composition on AD 198 encapsulation and liposomal size; (B) Effect of total

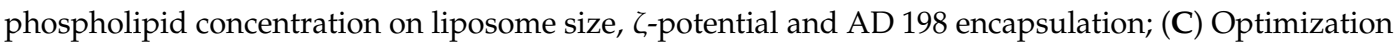
of HSPC concentration; (D) Effect of cholesterol concentration on AD 198 encapsulation and liposome

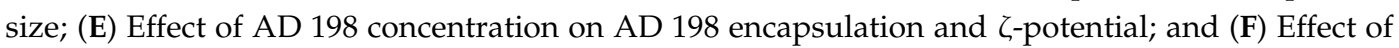
mPEG2000-DSPE concentration on $\zeta$-potential and liposome size.

\subsection{Effect of Total Phospholipids on AD 198 Encapsulation, Liposomal Size and $\zeta$-Potential}

Optimum concentration of HSPC was tested by comparing liposomes with 5 different concentrations of HSPC: 25, 50, 75, 100 and $125 \mathrm{mM}$. The drug concentration was kept constant at $2000 \mu \mathrm{g} / \mathrm{mL}$. The batch with $25 \mathrm{mM}$ HSPC failed to extrude. This may be attributed to the excess amount of drug in the system that the little amount of carrier (HSPC) would need to encapsulate. As seen from experiments, it is speculated that the un-encapsulated drug forms a thin layer on the membrane thus preventing the liposomes from extruding. The results for 50-125 mM HSPC are shown in Figure 3B. It would be logical to believe that with increase in the amount of HSPC in the system, 
which is the major encapsulating material, the amount of encapsulated drug would tend to increase. However, the results suggest that the amount of drug encapsulated may not necessarily be related to the amount of lipid in the system. This result can be explained with Figure $3 \mathrm{C}$ which indicates that during processing, a considerable amount of phospholipid was being lost as the total lipid content was increased beyond $75 \mathrm{mM}$. As portrayed in Figure 3C it was observed that the amount of HSPC loss during processing at $75 \mathrm{mM} \mathrm{HSPC}$ is approximately $25 \%$ (almost the same as $50 \mathrm{mM}$ ). However, at $100 \mathrm{mM}$ and $125 \mathrm{mM}$ the amount of phospholipid loss was more than $40 \%$, whereas the benefits in terms of AD 198 encapsulation and liposomal size were negligible (Figure 3B). Although there was a pronounced increase in the net negative charge on the liposomal surface, as depicted in Figure 3B, the size of the liposome increased considerably which allowed the conclusion of total phospholipid concentration at $75 \mathrm{mM}$ to be optimum for development purposes. An additional justification was that the extrusion time with total phospholipid concentration higher than $75 \mathrm{mM}$ increased considerably (more than 10 times).

There was an increase in the negative charge of the liposomes when the phospholipid concentration was increased from $50 \mathrm{mM}$ to $75 \mathrm{mM}$. This was followed by a reduced degree of increase from $75 \mathrm{mM}$ to $100 \mathrm{mM}$ and $125 \mathrm{mM}$ can possibly be explained by the excess amount of $\mathrm{AD}$ 198 that remains un-encapsulated. Since AD 198 has a cationic nature and HSPC an anionic nature, the excess AD 198 in the dispersion could be adsorbed onto the liposomal surface thus shielding the anionic nature of HSPC.

\subsection{Effect of Cholesterol Concentration on AD 198 Encapsulation and Liposomal Size}

Cholesterol is incorporated into the membrane to obtain an optimum bilayer fluidity $[67,70]$. However, with encapsulation of hydrophobic drugs in the bilayer it is important to consider effects of cholesterol concentrations on the encapsulation of the drug even before bilayer fluidity is considered. This is shown in Figure 3D which depicts the results from a study on the effects of increasing cholesterol concentrations. Four concentrations of cholesterol ranging from $5 \mathrm{mM}$ to $30 \mathrm{mM}$ were studied. Liposomal size was relatively similar for 5 and $10 \mathrm{mM}$ cholesterol concentrations. However, the size increased considerably at 15 and $30 \mathrm{mM}$ cholesterol. This may be attributed to the liposomal bilayer trying to accommodate both the AD 198 and the increasing cholesterol molecules which could possibly increase the liposomal size. AD 198 concentration reduced more than 10-fold from approximately $1000 \mu \mathrm{g} / \mathrm{mL}$ to $90 \mu \mathrm{g} / \mathrm{mL}$, when cholesterol concentration was increased from $15 \mathrm{mM}$ to $30 \mathrm{mM}$. Since part of the cholesterol molecular structure is similar to that of AD 198, the excess cholesterol molecules trying to occupy volume within the bilayer may be pushing out AD 198. This was also in agreement with the liposomal size results. Once excess AD 198 was pushed out, the liposomal size reduced by approximately $50 \mathrm{~nm}$. These results suggested that in view of AD 198 encapsulation and liposomal size, $10 \mathrm{mM}$ cholesterol concentration was optimum for LCLA. It should also be noted that with increasing cholesterol concentrations bilayer permeability decreases as demonstrated by Hu et al. [71], which is an advantage for long circulating liposomes.

\subsection{Effect of $A D 198$ Concentration on $A D 198$ Encapsulation and ऊ-Potential}

Five concentrations of AD 198 ranging from $500 \mu \mathrm{g} / \mathrm{mL}$ to $2500 \mu \mathrm{g} / \mathrm{mL}$ were tested to determine their effect on AD 198 encapsulation and $\zeta$-potential. Figure 3E shows that as the AD 198 concentration was increased from 500 to $1500 \mu \mathrm{g} / \mathrm{mL}$ the AD 198 encapsulation increased steadily. However, when the AD 198 concentration was increased from 1500 to $2000 \mu \mathrm{g} / \mathrm{mL}$, the AD 198 encapsulation almost doubled. However, if the AD 198 concentration was increased any further, there was not a considerable increase in AD 198 encapsulation. The $\zeta$-potential was relatively constant up to $2000 \mu \mathrm{g} / \mathrm{mL}$. However, once the AD 198 concentration reached $2500 \mu \mathrm{g} / \mathrm{mL}$, the electronegativity of the particles reduced. Again, this can be attributed to the excess un-encapsulated cationic AD 198 adsorbing onto the predominantly anionic HSPC liposomes, which will shield the negative charge due to HSPC. Hence, 
$2000 \mu \mathrm{g} / \mathrm{mL}$ was selected as the optimum AD 198 concentration and hereon this was the concentration used for further studies.

\subsection{Optimization of mPEG2000-DSPE Concentration}

To determine the optimum amount of mPEG2000-DSPE, four concentrations of mPEG2000-DSPE ranging from 1 to 5 mole \% were studied. Figure $3 F$ represents the effect of mPEG2000-DSPE concentration on liposomal size and $\zeta$-potential. The liposomal size was observed to increase with increasing concentrations of mPEG2000-DSPE. Conversely, $\zeta$-potential was observed to turn more electronegative with an increase in MPEG2000-DSPE concentration which may be attributable to the anionic nature of mPEG2000-DSPE. mPEG2000-DSPE is a large molecule (MW = 2805.497). The increase in the number of mPEG2000-DSPE molecules may cause the net size of the liposome to increase as justified by Woodle and co-workers [72]. However, the 2 mole \% mPEG2000-DSPE imparted optimum size and $\zeta$-potential to the formulation and this was selected for further studies.

\subsection{LCLA Drug Release}

LCLA was tested for its release characteristics in $1 \times \mathrm{PBS}$ at $37^{\circ} \mathrm{C}$. Figure 4 shows that approximately 30\% AD 198 release was observed over the first $12 \mathrm{~h}$ following which only about 10\% more AD 198 was released over the next $48 \mathrm{~h}$. This may be due a biphasic release mechanism in which the drug is released in two separate phases. Initially the drug was released in a burst mode from drug simply adhered to the liposomal surface, followed by the release of drug from the liposomal bilayer. Possibly there may be micelles formed from the monomer lipid molecules which were not incorporated into liposomes. If these monomer lipids are above their critical micelle concentration (CMC), they will form micelles. Micelles are less stable compared to liposomes and may release drug faster than liposomes. Once micelle drug release is over the liposomal AD 198 release predominantly determines the kinetics. The release pattern is necessary with the theory of active targeting in which the liposome requires a certain period of time before it encounters a $\mathrm{CD} 22^{+}$malignant $\mathrm{B}$ cell, binds to it and is internalized. The drug must largely be released once the liposome is inside the malignant cell. Therefore, the delayed release of AD 198 over $>72 \mathrm{~h}$ is beneficial for the LCLA drug delivery system.

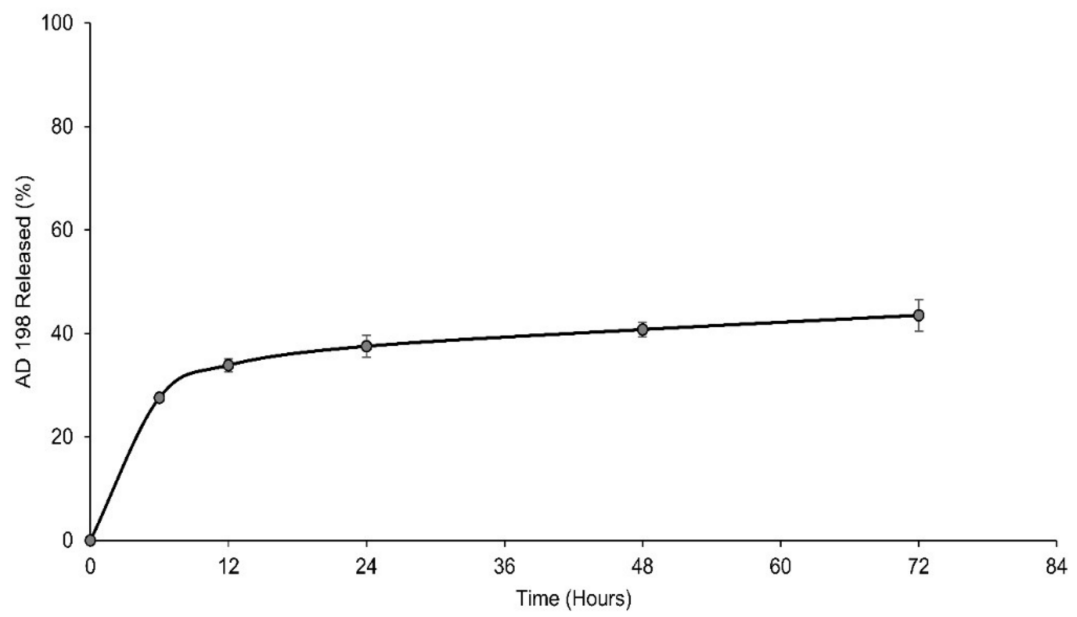

Figure 4. AD 198 release profile from LCLA at $37^{\circ} \mathrm{C}$.

\subsection{Number of AD 198 Molecules/Liposome}

The number of average HSPC molecules per $\mathrm{mL}$ of the LCLA was calculated by using the Avogadro's number, $6.023 \times 10^{23}$ molecules/mole. This gave an average of $3.25 \times 10^{22} \mathrm{HSPC}$ molecules/mL of LCLA as per the analyzed concentration of HSPC, $54 \mathrm{mM}$ from the HSPC assay results. The number of average AD 198 molecules/mL of LCLA were calculated similarly from 
the analyzed concentration of AD 198 to be $1250 \mu \mathrm{g} / \mathrm{mL}$. This gave an average of $1.05 \times 10^{21} \mathrm{AD}$ 198 molecules/mL of LCLA. The outer surface area of the liposomal bilayer was calculated from Equation (1).

$$
\text { Outer Surface Area }=4 \pi r^{2}
$$

Here ' $r$ ' was the average outer radius of the liposome. The thickness of the bilayer was denoted ' $h$ ' and is $5 \mathrm{~nm}$ [73]. Then the inner surface area was calculated from Equation (2).

$$
\text { Inner Surface Area }=4 \pi(r-h)^{2}
$$

The cross-sectional area of a phosphatidylcholine headgroup was denoted as ' $a$ ' with a value of $0.71 \mathrm{~nm}^{2}[74]$ and the number of HSPC molecules per liposome calculated from Equation (3).

$$
\begin{gathered}
\text { Number of HSPC molecules/liposome }=\frac{4 \pi\left[r^{2}+(r-h)^{2}\right]}{a} \\
\text { Number of HSPC molecules/liposome }=\frac{17.69\left[60^{2}+(60-5)^{2}\right]}{0.71}=117196
\end{gathered}
$$

This gave us the number of liposomes/mL from Equation (4).

$$
\begin{gathered}
\text { Number liposomes } / \mathrm{mL}=\frac{\text { Number of HSPC molecules } / \mathrm{mL}}{\text { Number of HSPC molecules } / \text { liposome }} \\
\text { Number liposomes } / \mathrm{mL}=\frac{3.25 \times 10^{22}}{117196}=2.77 \times 10^{17}
\end{gathered}
$$

Number of average AD 198 molecules per liposome were calculated from Equation (5).

$$
\text { Number of AD } 198 \text { molecules } / \text { liposome }=\frac{\text { Number of AD } 198 \text { molecules } / \mathrm{mL}}{\text { Number of liposomes } / \mathrm{mL}}
$$

$$
\text { Number of AD } 198 \text { molecules } / \text { liposome }=\frac{1.05 \times 10^{21}}{2.77 \times 10^{17}}=3790
$$

\subsection{Verification of Anti-CD22 Fab' Conjugation}

A western blot of the LCCTLA was run with pure antibody digest fractions and the whole antibody. The results are shown in Figure 5. The whole antibody gave a very intense band at the $150 \mathrm{kD}$ region whereas the concentration of protein for the fraction below $50 \mathrm{kD}$ was very low and bands relatively faint. Figure 5A shows the possible combinations of the antibody digests that may be produced and may show up on the blot. Fab' would be $50 \mathrm{kD}$ each, $\mathrm{F}\left(\mathrm{ab}^{\prime}\right)_{2}$ would be $100 \mathrm{kD}$, the Fc region has been digested by pepsin thus would be broken into very small peptides possible smaller than $10 \mathrm{kD}$, and undigested antibody would be $150 \mathrm{kD}$.

In Figure 5B in the first three lanes are for pure antibody and digests. Lane 1 is undigested whole antibody, lane 2 is the digested Fab' fragment and lane 3 is the fraction above $100 \mathrm{kD}$. The last lane is LCCTLA and here we observed a clear band at approximately $50 \mathrm{kD}$. Since we had removed other fragments such as the Fc pepsin digests and whole antibody from the 50 to $100 \mathrm{kD}$ fraction, this was possibly the band for the anti-CD22 Fab'. The whole antibody is shown beside the LCCTLA lane for reference purposes. The appearance of a strong band at $50 \mathrm{kD}$ in the LCCTLA sample proved that conjugation between the liposomes and the Fab' was successful. 
(A)

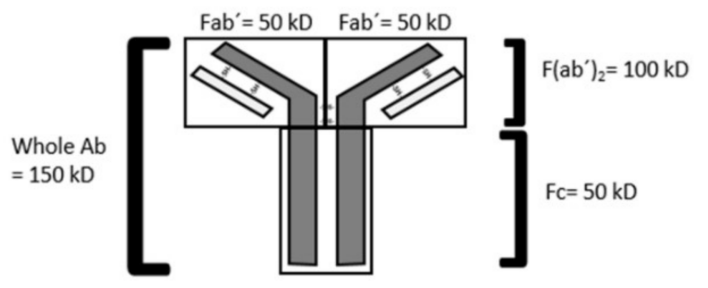

(B)

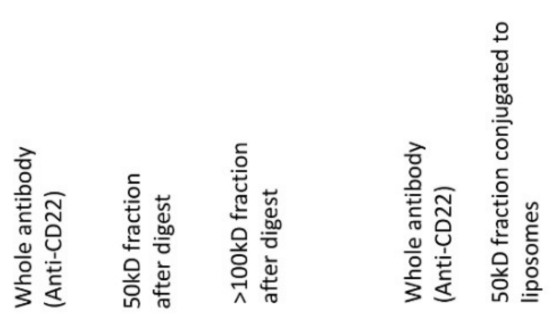

$150 \mathrm{kD}$

$100 \mathrm{kD}$

$55 \mathrm{kD}$

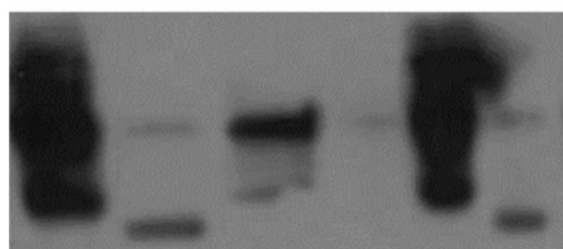

Figure 5. (A) Verification of anti-CD22 Fab' conjugation; (B) Verification of conjugation of anti-CD22 Fab' by western blotting.

\subsection{Number of Anti-CD22 Fab' and Maleimide per LCCTLA}

$2.2 \mathrm{mg} / \mathrm{mL}$ of mal-PEG2000-DSPE was added to make LCCTLA particles. This equals $748 \mu \mathrm{M}$ of mal-PEG2000-DSPE. Using Avogadro's number, we got an average of $4.5 \times 10^{20}$ mal-PEG2000-DSPE molecules $/ \mathrm{mL}$. As specified in the method, the number of maleimide's per liposome can be calculated by Equation (6).

$$
\text { No. of maleimide molecules } / \text { liposome }=\frac{\text { No. of maleimide molecules } / \mathrm{mL}}{\text { No. of liposomes } / \mathrm{mL}}
$$

$$
\text { Number of maleimide molecules/liposome }=\frac{4.5 \times 10^{20}}{2.77 \times 10^{17}} \approx 1626
$$

The average number of anti-CD22 Fab' molecules were calculated in a similar method. The analyzed concentration of Fab' fragments in LCCTLA was $313 \mu \mathrm{g} / \mathrm{mL}$ which equals $6.26 \mu \mathrm{M}$. Using Avogadro's number, the number of anti-CD22 Fab' molecules/mL were calculated to be $3.77 \times 10^{18}$ molecules/mL. Substituting these numbers into Equation (7):

$$
\begin{gathered}
\text { Number of Fab' /liposome }=\frac{\text { Number of Fab' } / \mathrm{mL}}{\text { Number of liposomes } / \mathrm{mL}} \\
\text { Number of } \mathrm{Fab}^{\prime} / \text { liposome }=\frac{3.77 \times 10^{18}}{2.77 \times 10^{17}} \approx 13 \text { antiCD22 Fab' /liposome }
\end{gathered}
$$

The physicochemical properties of the liposomes after anti-CD22 Fab' conjugation was as follows: mean size was $148.6 \pm 4 \mathrm{~nm}$, mean $\zeta$-potential was $-10.7 \pm 2 \mathrm{mV}$ and average drug encapsulation was about $400 \mu \mathrm{g} / \mathrm{mL}$.

\subsection{Cellular Uptake of LCLA and LCCTLA}

Flow cytometry and confocal laser scanning microscopy (CLSM) were utilized to determine the uptake of LCLA and LCCTLA in CD22 expressing Daudi and CD22 non-expressing Jurkat cells. Figure 6A summarizes the results for cellular uptake of both formulations in both Daudi and Jurkat cells. It was observed that the maximum uptake at each time point was for LCCTLA in Daudi cells. The least uptake was seen with LCLA treated Jurkat cells at every time point. Daudi cells treated with LCLA and Jurkat cells treated with LCCTLA had intermediate uptake. Maximum uptake in Daudi cells treated with LCCTLA was understandable due to the CD22 receptor being overexpressed on the Daudi cells and the LCCTLA having the antibody for this overexpressed receptor. However, the Jurkat 
cells having higher uptake with LCCTLA than LCLA is more complicated to explain. One theory we suggest is that the Jurkat cells may have some receptor on their surface with which the anti-CD22 Fab' non-specifically interacts, thus causing higher uptake. Also, it was seen for Daudi cells treated with LCCTLA, the uptake plateaued at approximately one hour. Therefore, maximum uptake had already taken place by one hour.
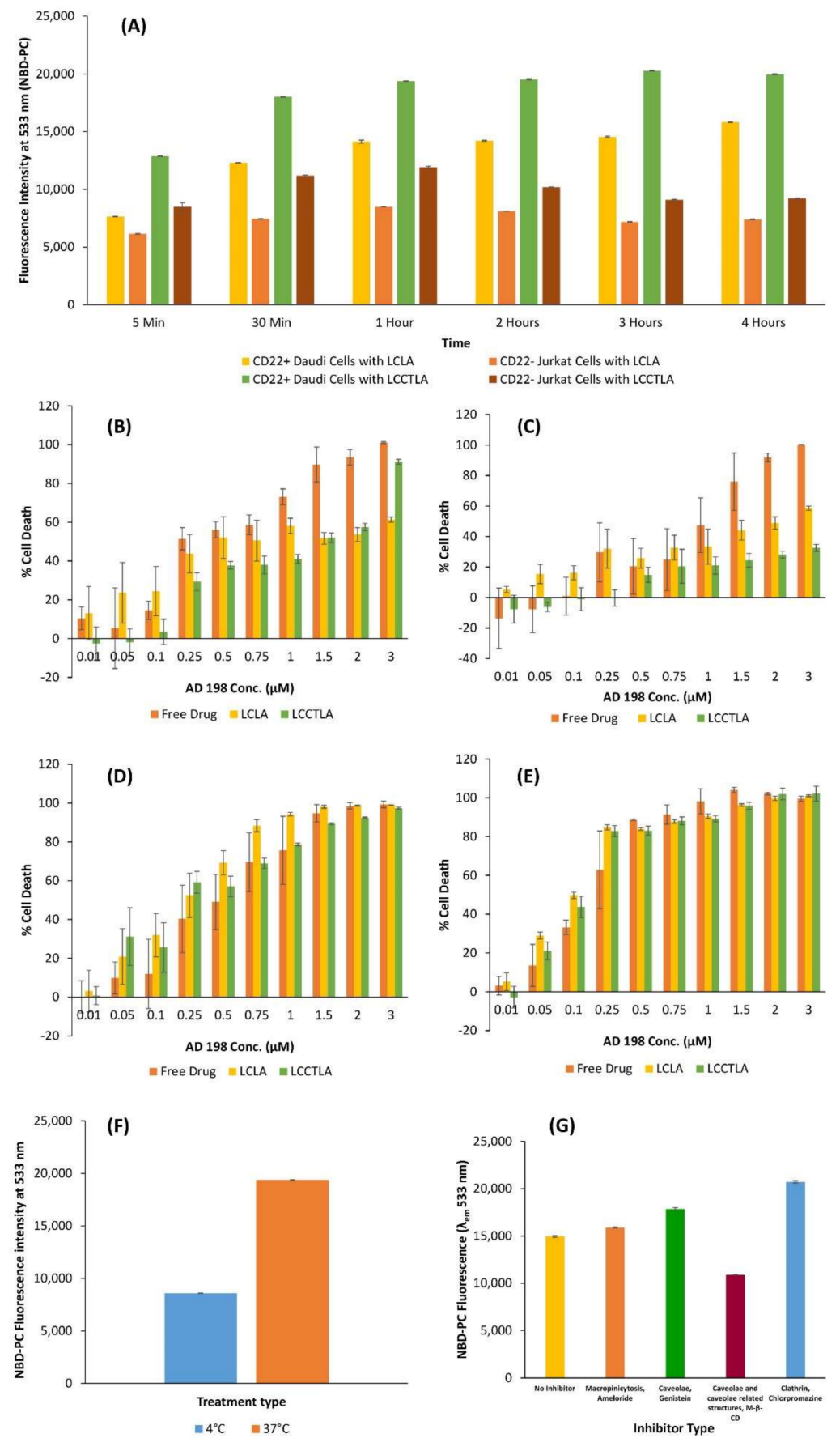

Figure 6. (A) Time-dependent cell uptake of LCLA and LCCTLA (long circulating CD22 targeted liposomal AD 198) in Daudi and Jurkat cells; (B) 24 h Daudi AD 198 cytotoxicity; (C) 24 h Jurkat AD 198 cytotoxicity; (D) 48 h Jurkat cytotoxicity; (E) 48 h Daudi cytotoxicity; (F) Cell association of LCCTLA in Daudi cells; and (G) LCCTLA uptake in Daudi cells under different inhibitors. 


\subsection{Analysis of Cytotoxicity of LCCTLA}

Three formulations of AD 198 (free AD 198, LCLA and LCCTLA) were tested in Daudi and Jurkat cells. The study was performed to test the cytotoxic effect of the formulations at two lengths of exposure, 24 and $48 \mathrm{~h}$. Figure $6 \mathrm{~B}$ to $6 \mathrm{E}$ depict the results of this study. Figure $6 \mathrm{~B}$ exhibits the cytotoxic effects of the three formulations, free drug, LCLA and LCCTLA over $24 \mathrm{~h}$ in Daudi cells. The difference in cytotoxicity between different formulations is clearly pronounced. From $0.01 \mu \mathrm{M}$ to $3 \mu \mathrm{M}$ AD 198 concentration, free AD 198 is most cytotoxic, with an $\mathrm{IC}_{50}$ of approximately $0.25 \mu \mathrm{M}$, as shown in Table 1 below. LCLA has an $\mathrm{IC}_{50}$ at about $0.5 \mu \mathrm{M}$, but LCCTLA have an $\mathrm{IC}_{50}$ of about $1.5 \mu \mathrm{M}$. Up to $1 \mu \mathrm{M}$ LCLA was more cytotoxic than LCCTLA and almost equally cytotoxic at $1.5 \mu \mathrm{M}$. At $2 \mu \mathrm{M}$ and $3 \mu \mathrm{M}$, LCCTLA displayed higher cytotoxicity. This may be attributable to the process of receptor-mediated endocytosis which may possibly require additional time to endocytose the targeted liposomes. The Jurkat cells are devoid of the CD22 receptors and thus we observed the results as displayed in Figure 6C, which are the results of the 24-h study in Jurkat cells. Since the CD22 receptor is absent in Jurkat cells, LCCTLA was not as cytotoxic as LCLA or free AD 198.

Table 1. IC50 values for the formulation in Daudi and Jurkat cells.

\begin{tabular}{ccccccc}
\hline Study Duration & \multicolumn{3}{c}{$\mathbf{2 4} \mathbf{h}$} & & $\mathbf{4 8 ~ h}$ & \\
\hline Formulation Type & Free Drug & LCLA & LCCTLA & Free Drug & LCLA & LCCTLA \\
\hline $\begin{array}{c}\text { Cancer Cell Type } \\
\text { Daudi }\end{array}$ & 0.243 & 0.481 & 1.443 & 0.199 & 0.101 & 0.114 \\
Jurkat & 1.054 & 2.046 & $4.608^{*}$ & 0.509 & 0.238 & 0.438 \\
\hline
\end{tabular}

LCLA: Untargeted long circulating liposomal AD 198; LCCTLA: Long circulating CD22 targeted liposomal AD 198.

In the 48-h study, a steadily increasing cell death pattern was noticed in both Jurkat (Figure 6D) and Daudi cells (Figure $6 \mathrm{E}$ ) from $0.01 \mu \mathrm{M}$ to $0.5 \mu \mathrm{M}$ for all formulations. Then from $0.75 \mu \mathrm{M}$ up to $3 \mu \mathrm{M}$, there is not much of a pronounced difference between concentrations and between the formulations. This result may be attributed to the overburdening of the cells with the drug in all types of formulations. Since the drug is not being cleared as in in vivo systems, all the drug from the formulation eventually enters the cells and kills them. This may be controlled by developing a system that would mimic blood circulation as in whole animals. One such model was developed by Budha et al. at the University of Tennessee Health Science Center [75]. Nevertheless, in vivo models would give more accurate representations of how the drug would behave in clinical settings.

\subsection{Cellular Association}

Figure $6 \mathrm{~F}$ shows the results of the cellular association studies. It was observed that the LCCTLA uptake in Daudi cells was significantly reduced when the uptake study was being performed at $4{ }^{\circ} \mathrm{C}$ compared to when it was done at $37^{\circ} \mathrm{C}$. Receptor-mediated endocytosis is a specific process that requires ATP for appropriate functioning and is also temperature dependent (with optimum temperature being $37^{\circ} \mathrm{C}$ ) [76]. It may be possible that the reduced uptake in the $4{ }^{\circ} \mathrm{C}$ study group was due to the uptake mechanism for the LCCTLA being receptor-mediated endocytosis. Since the mechanism is greatly reduced and even possible halted, the uptake seen may be a result of the receptor associated LCCTLA being internalized before the washes were done. This result suggests that the mechanism of uptake of LCCTLA into CD22 expressing Daudi cells is receptor-mediated endocytosis.

\subsection{LCCTLA Particles Are Endocytosed into Cells by a Clathrin- and Caveolae-Independent Pathway}

Figure $6 \mathrm{G}$ shows the results for LCCTLA uptake under the effect of inhibitors for certain specific pathways. The control data is for uptake results under no inhibitor use. Compared to the control, the only pathway that was significantly inhibited was caveolae and caveolae related structures. All other pathways, macropinocytosis, caveolae-mediated internalization and clathrin-mediated internalization, LCCTLA uptake seems to have somewhat increased significantly. The results are not clear as to 
why the uptake is increasing in most pathways under inhibitor use and decreasing in one (similar to caveolae mediated uptake, in which the uptake increased). It is possible that none of these pathways is the mechanism for uptake of LCCTLA in CD22 expressing Daudi cells, which suggests that LCCTLA uptake could be via the fourth pathway which is independent of clathrin and caveolin proteins and that the uptake of LCCTLA was not affected in the presence of these inhibitors because its uptake was not dependent on those pathways [77]. This complete mechanism of this pathway is not yet fully understood especially during the late stage of vesicle formation.

\subsection{LCCTLA Nanoparticles Were Localized Intracellularly in Endosomes}

Figure 7A shows a whole Daudi cell image acquired by TEM post-MLCCTLA treatment. Two parts of the image have been enlarged in Figure 7B,C. As in Figure 7B an MLV inside an endocytotic vesicle can be observed. The size of each of the three dark structures inside the vesicle are approximately $70 \mathrm{~nm}$ in diameter, indicating that these are the SUV's inside the outer, larger MLV. In Figure 7C another endocytotic vesicle carrying SUV's was observed. These SUV's are approximately $50 \mathrm{~nm}$ in diameter. The size of these vesicles corresponds with the size of the MLCCTLA (data not shown here). This data confirms that the intracellular localization of the MLCCTLA is in endosomes. Later, these endosomes must fuse with lysosomes to form endolysosomes to release AD 198 [78].

\subsection{The Endosomes Fuse with Lysosomes to Give Endolysosomes}

Figure 7D shows the images for the study to determine if the endosome in which the LCCTLA were localized were endolysosomes. The cells shown here are Daudi cells treated with $10 \mu \mathrm{L}$ of placebo LCCTLA and LysoTracker ${ }^{\circledR}$ Deep Red (a dye that binds to late endolysosomes). After washing off the excess placebo LCCTLA, the images showed red circular structures inside the Daudi cells (white arrows). Since the dye for tagging the endolysosomes was red, it was deduced that these circular red structures were the endolysosomes. The liposomes were processed with NBD-PC, a fluorescent green lipid, which also show up in the images as bright green (green arrows). When these two images were overlaid, it was observed that the endolysosomes and the LCCTLA were co-localized inside the cells (yellow arrows). This establishes that the LCCTLA were intracellularly localized in endosomes (as from Figure $7 \mathrm{~B}, \mathrm{C}$ ) and these endosomes were later fusing with the lysosomes to give endolysosomes (Figure 7D).

\subsection{LCCTLA Activates Classical Apoptotic Pathways}

With LCCTLA treatment in Daudi cells, it was observed that expression of oncogenic markers decreased, and apoptotic markers increased. Figure $8 \mathrm{~B}$ shows the proteins that were affected along with their functions and Figure 8A gives a comparison of their expressions with the control. C-myc is a marker for Burkitt's lymphoma and is a regulator gene that codes for a transcription factor [79]. The protein is multi-functional playing roles in apoptotic inhibition and cell cycle progression. Treatment with LCCTLA reduced the expression of c-myc in a time-dependent manner as shown in Figure 8A. Similar results were also demonstrated by Edwards et al. [45].

LCCTLA, once internalized is believed to release drug due to $\mathrm{pH}$ reduction in the endolysosomes. The intracellularly released AD 198 binds to PKC holoenzyme. Later the catalytic segment (CS) dissociates. The CS activates PLS3 which depolarizes the mitochondria releasing Cyt C. The Cyt C activates caspase 3. Caspase 3 being an apoptotic protein eventually results in apoptosis [40]. Thus, we observed a time-dependent increase in the concentration of caspase 3 as depicted in Figure 8A, which is a hallmark of cell death via apoptosis. There is a possibility for AD 198 to activate caspase-3 by other pathways but these are not well understood yet.

Protein kinase B also known as Akt is a serine-threonine specific protein kinase which plays a key role in multiple process in the cell such as cell proliferation, transcription, and apoptosis. It is capable of initiating cell survival via growth factor dependent and independent pathways [80]. Phosphorylated Akt is the activated form of Akt which is necessary for it to activate or deactivate its 
substrates [81,82]. In Figure 8A, we observed the expression of pAKT decreasing in a time-dependent manner compared to the control, which means that LCCTLA also inhibited cell proliferation via suppression of pAKT. JNK's or c-Jun N-terminal kinases are master protein kinases that regulate many processes in the cell such as inflammation, cell proliferation and differentiation and apoptosis. They belong to the mitogen-activated protein kinase family. Their active role in cancer development is now well-established [83]. JNK is activated by phosphorylation (pJNK). pJNK in turn phosphorylates multiple protein depending on its isoform. Figure 8A shows a time-dependent suppression of pJNK by treatment of Daudi cells with LCCTLA, thus proving that cell proliferation is also inhibited by suppression of pJNK.
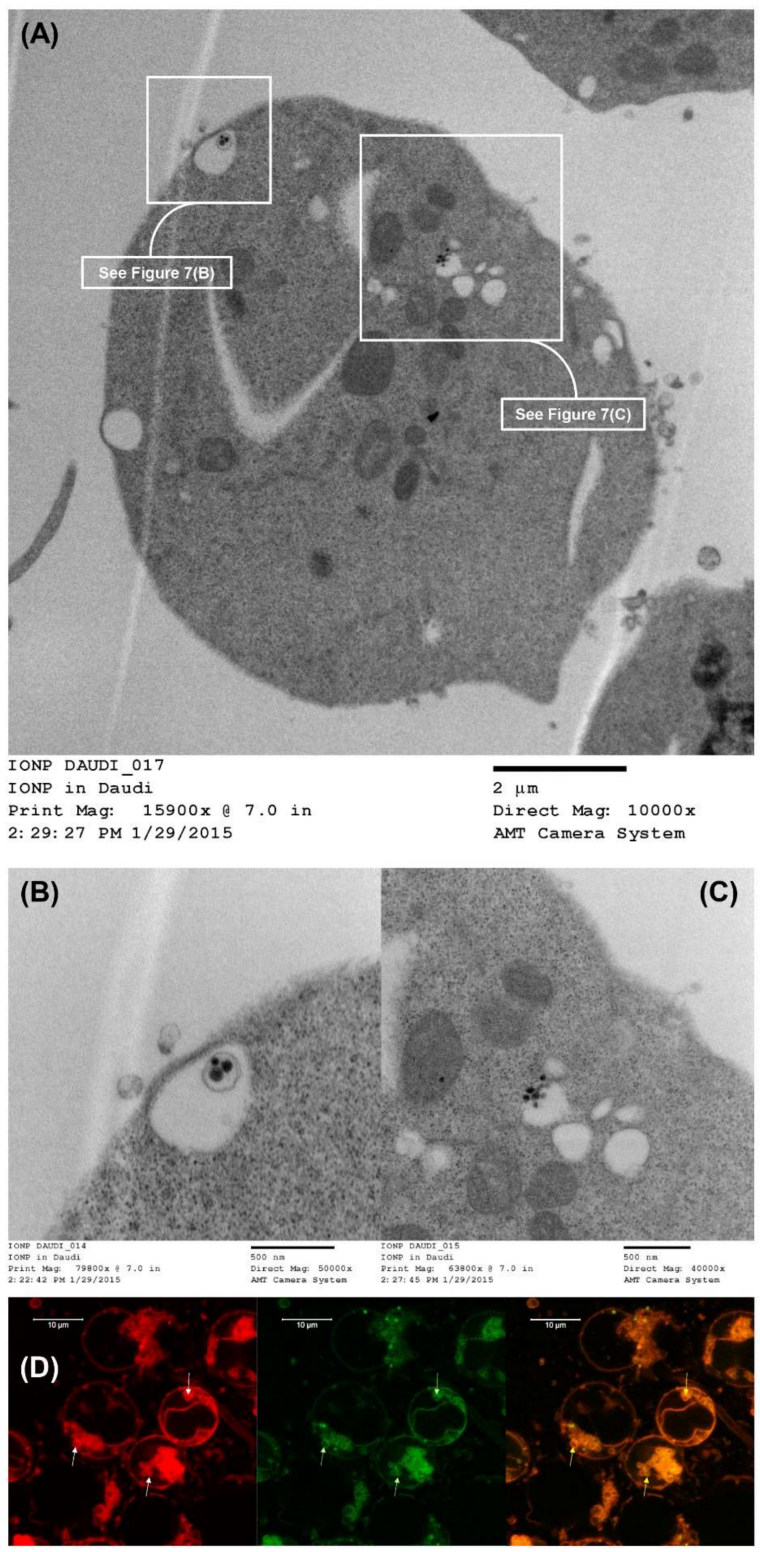

Figure 7. (A) TEM image of LCCTLA intracellular localization in Daudi cells; (B) Enlarged from Figure 7A showing an MLV of MLCCTLA inside an endosomal structure; (C) Enlarged from Figure 7A showing SUV's of MLCCTLA inside an endosomal structure; and (D) CLSM image of intracellular localization of LCCTLA in endolysosomes. 


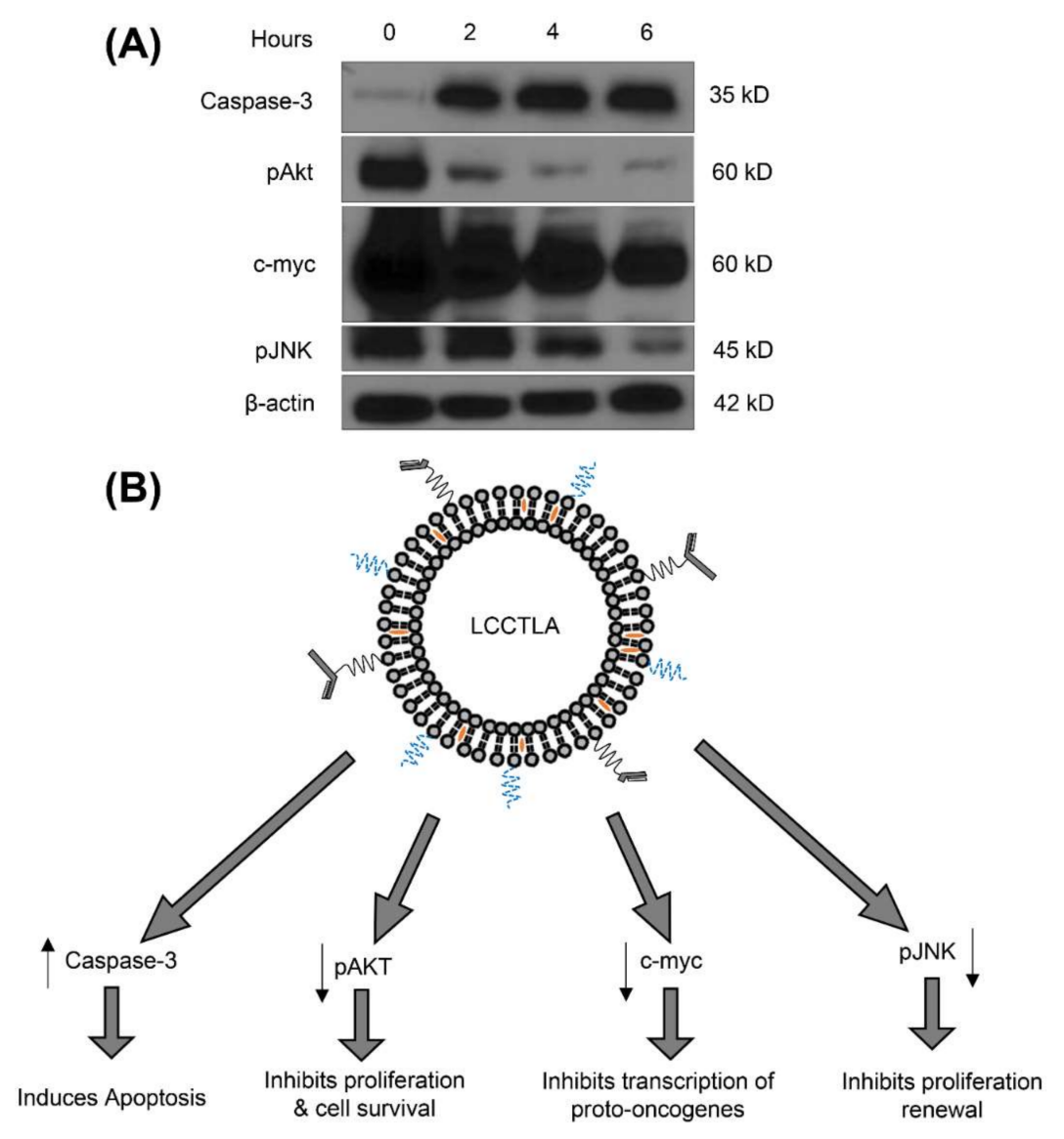

Figure 8. (A) Western blot results for the expression patterns post LCCTLA treatment for 3 time points, 2, 4 and $6 \mathrm{~h}$; and (B) Effect of LCCTLA on the expression of caspase-3, pAKT, c-myc and pJNK.

\section{Summary and Conclusions}

A prototype formulation of AD 198 loaded liposomes (LCLA) was developed that would be able to encapsulate maximum AD 198 and have optimum parameters for effective delivery of the encapsulated drug. The optimized composition of LCLA was as follows. HSPC was the lipid of choice and was used at 75 mole \%, mPEG2000-DSPE 2 mole \%, cholesterol 10 mole $\%$ and AD $1982 \mathrm{mg} / \mathrm{mL}$. The physicochemical parameters of the optimized formulation were as follows; size 115-145 nm,

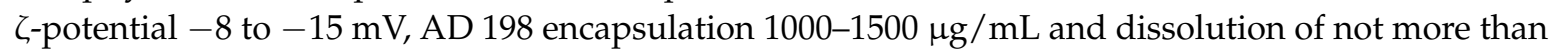
$30 \%$ AD 198 occurred for $72 \mathrm{~h}$. The size of the LCLA as per TEM was found be in the range of $80-90 \mathrm{~nm}$. TEM micrographs indicated a roughly spherical morphology of the liposomes. It was calculated that the number of HSPC molecules per liposome were approximately 117,196 and the number of AD 198 molecules were approximately 3790 per liposome.

To achieve active targeting, it was necessary to conjugate a ligand for a specific receptor on the surface of the malignant B cells. For this purpose, CD22 was selected as the receptor to be targeted on the malignant $B$ cells. CD22 was selected due to its property of receptor mediated endocytosis upon interaction with the ligand and because it was overexpressed in malignant B cells. The anti-CD22 monoclonal antibody, RFB4, was selected as the targeting ligand. Since earlier studies by other research groups had proven that the circulating half-life of targeted liposomal systems was higher if targeted using just the Fab' conjugated to the liposomes rather than the whole antibody, only the anti-CD22 Fab' conjugation was optimized. Numerous methods for conjugating a ligand to the liposome exist. The one selected for conjugating the anti-CD22 Fab' to the LCLA was with the thioether bond. The reason for selecting this strategy was its minimum use of harsh reagents and provision of a strong covalent chemical bond ensuring the stability of the targeted liposomal system. Proof of conjugation by the 
thioether bonding was provided by a western blot of the targeted liposomes which evidently portrayed a band at the $50 \mathrm{kD}$ region which was the molecular weight of the anti-CD22 Fab'. It was calculated that every liposome displayed an average of approximately 13 anti-CD22 Fab' molecules.

Whether or not the 13 anti-CD22 Fab' molecules were sufficient to effectively target and deliver the liposomal AD 198 to the malignant B cells was determined by testing the long-circulating CD22 targeted liposomal AD 198 (LCCTLA), in vitro in CD22 overexpressing Daudi cells and comparing this result with non-CD22 expressing Jurkat cells. It was seen that Daudi cells had a significantly higher uptake of the LCCTLA compared to Jurkat cells, which confirmed specificity of the delivery system. The MTT assay results for cell cytotoxicity suggested a delay in cell kill for Daudi cells treated with LCCTLA, but this could be explained by the method of endocytosis that they underwent which would take more time compared to the diffusion mechanism for LCLA and solution AD 198. Nevertheless, cytotoxicity by the LCCTLA in Daudi cells was highest for a 24-h study. However, the results from the 48-h study suggest that studies in animals need to be performed in which unbound drug would be cleared faster, and this would mimic clinical settings better.

The functioning of LCCTLA was explained by the several studies performed in vitro. Cellular association studies determined that the endocytotic mechanism was an energy dependent mechanism and it was further ascertained that the mechanisms of endocytosis possibly were a clathrinand caveolin-independent pathway. This pathway has not been fully understood yet particularly the later stages of internalization. However, it was successfully determined that after endocytosis, the liposomes were localized in endolysosomes. This result suggested that the drug release would take place due to liposomal breakdown by the low lysosomal $\mathrm{pH}$. Once the drug was released into the cytosol, it functioned via the activation of apoptotic proteins such as caspase- 3 and the suppression of oncoproteins such as c-myc. These verifications were deduced by protein expression studies performed in Daudi cells post-LCCTLA treatment.

In conclusion, targeted drug delivery with AD 198 was more potent and specific compared to other untargeted formulations. Further studies in small animal models are necessary to ascertain the efficacy of the system in more clinically relevant models.

Acknowledgments: The authors would like to acknowledge The University of Tennessee Health Science Center, College of Pharmacy, Department of Pharmaceutical Sciences, Plough Center for Sterile Drug Delivery Systems, and all supporting labs for their constant support of this work. The authors would also like to acknowledge the lab of Ellen Vitetta, University of Texas, Southwestern Medical Center, for providing valuable molecules from their lab without which this study would not have been possible.

Author Contributions: This original research has been conceived and designed by Nivesh K. Mittal, with valuable inputs from the rest of the authors. Experiments were conducted by Nivesh K. Mittal, Pavan Balabathula, Bivash Mandal, Saini Setua and Dileep R. Janagam, under the guidance of George C. Wood, Leonard Lothstein and Laura Thoma. Data Analysis was performed by all authors. Laura Thoma, George C. Wood and Leonard Lothstein provided materials and equipment for the experiments and Nivesh K. Mittal wrote the paper.

Conflicts of Interest: The authors declare no conflict of interest.

\section{References}

1. Barenholz, Y.C. Doxil ${ }^{\circledR}$-The first FDA-approved nano-drug: Lessons learned. J. Control. Release 2012, 160, 117-134. [CrossRef] [PubMed]

2. Venditto, V.J.; Szoka, F.C., Jr. Cancer nanomedicines: So many papers and so few drugs! Adv. Drug Deliv. Rev. 2013, 65, 80-88. [CrossRef] [PubMed]

3. Green, M.R.; Manikhas, G.M.; Orlov, S.; Afanasyev, B.; Makhson, A.M.; Bhar, P.; Hawkins, M.J. Abraxane, a novel cremophor-free, albumin-bound particle form of paclitaxel for the treatment of advanced non-small-cell lung cancer. Ann. Oncol. 2006, 17, 1263-1268. [CrossRef] [PubMed]

4. Petre, C.E.; Dittmer, D.P. Liposomal daunorubicin as treatment for kaposi's sarcoma. Int. J. Nanomed. 2007, 2, 277-288. 
5. Deitcher, O.R.; O'Brien, S.; Deitcher, S.R.; Thomas, D.A.; Kantarjian, H.M. Single-agent vincristine sulfate liposomes injection (marqibo ${ }^{\circledR}$ ) compared to historical single-agent therapy for adults with advanced, relapsed and/or refractory philadelphia chromosome negative acute lymphoblastic leukemia. Blood 2011, $118,2592$.

6. Rodriguez, M.; Pytlik, R.; Kozak, T.; Chhanabhai, M.; Gascoyne, R.; Lu, B.; Deitcher, S.R.; Winter, J.N. Vincristine sulfate liposomes injection (marqibo) in heavily pretreated patients with refractory aggressive non-hodgkin lymphoma. Cancer 2009, 115, 3475-3482. [CrossRef] [PubMed]

7. Bharali, D.J.; Mousa, S.A. Emerging nanomedicines for early cancer detection and improved treatment: Current perspective and future promise. Pharmacol. Ther. 2010, 128, 324-335. [CrossRef] [PubMed]

8. Davis, M.E.; Chen, Z.G.; Shin, D.M. Nanoparticle therapeutics: An emerging treatment modality for cancer. Nat. Rev. Drug Discov. 2008, 7, 771-782. [CrossRef] [PubMed]

9. Torchilin, V.P. Immunoliposomes and pegylated immunoliposomes: Possible use for targeted delivery of imaging agents. ImmunoMethods 1994, 4, 244-258. [CrossRef] [PubMed]

10. Allen, T.M. Ligand-targeted therapeutics in anticancer therapy. Nat. Rev. Cancer 2002, 2, 750-763. [CrossRef] [PubMed]

11. Allen, T.M.; Mumbengegwi, D.R.; Charrois, G.J.R. Anti-CD19-targeted liposomal doxorubicin improves the therapeutic efficacy in murine b-cell lymphoma and ameliorates the toxicity of liposomes with varying drug release rates. Clin. Cancer Res. 2005, 11, 3567-3573. [CrossRef] [PubMed]

12. Allen, T.M.; Sapra, P.; Moase, E. Use of the post-insertion method for the formation of ligand-coupled liposomes. Cell. Mol. Biol. Lett. 2002, 7, 217-219. [PubMed]

13. Cheng, W.W.; Allen, T.M. Targeted delivery of anti-CD19 liposomal doxorubicin in b-cell lymphoma: A comparison of whole monoclonal antibody, fab' fragments and single chain fv. J. Control. Release 2008, 126, 50-58. [CrossRef] [PubMed]

14. De Menezes, D.E.L.; Kirchmeier, M.J.; Gagne, J.F.; Pilarski, L.M.; Allen, T.M. Cellular trafficking and cytotoxicity of anti-CD19-targeted liposomal doxorubicin in b lymphoma cells. J. Liposome Res. 1999, 9, 199-228. [CrossRef]

15. Pillai, G. Nanomedicines for cancer therapy: An update of fda approved and those under various stages of development. SOJ Pharm. Pharm. Sci. 2014, 1, 1-13.

16. Allen, T.M.; Cullis, P.R. Liposomal drug delivery systems: From concept to clinical applications. Adv. Drug Deliv. Rev. 2013, 65, 36-48. [CrossRef] [PubMed]

17. Bulbake, U.; Doppalapudi, S.; Kommineni, N.; Khan, W. Liposomal formulations in clinical use: An updated review. Pharmaceutics 2017, 9, 12. [CrossRef] [PubMed]

18. Torchilin, V.P. Recent advances with liposomes as pharmaceutical carriers. Nat. Rev. Drug Discov. 2005, 4, 145-160. [CrossRef] [PubMed]

19. Heger, Z.; Polanska, H.; Rodrigo, M.A.M.; Guran, R.; Kulich, P.; Kopel, P.; Masarik, M.; Eckschlager, T.; Stiborova, M.; Kizek, R. Prostate tumor attenuation in the nu/nu murine model due to anti-sarcosine antibodies in folate-targeted liposomes. Sci. Rep. 2016, 6, 33379. [CrossRef] [PubMed]

20. Dothager, R.S.; Piwnica-Worms, D. Nano in cancer: Linking chemistry, biology, and clinical applications in vivo. Cancer Res. 2011, 71, 5611-5615. [CrossRef] [PubMed]

21. Ali, I.; Salim, K.; Rather, M.A.; Wani, W.A.; Haque, A. Advances in nano drugs for cancer chemotherapy. Curr. Cancer Drug Targ. 2011, 11, 135-146. [CrossRef]

22. Siegel, R.L.; Miller, K.D.; Jemal, A. Cancer statistics, 2015. CA A Cancer J. Clin. 2015, 65, 5-29. [CrossRef] [PubMed]

23. Chen, W.C.; Completo, G.C.; Sigal, D.S.; Crocker, P.R.; Saven, A.; Paulson, J.C. In vivo targeting of b-cell lymphoma with glycan ligands of cd22. Blood 2010, 115, 4778-4786. [CrossRef] [PubMed]

24. Tirelli, U.; Errante, D.; Van Glabbeke, M.; Teodorovic, I.; Kluin-Nelemans, J.; Thomas, J.; Bron, D.; Rosti, G.; Somers, R.; Zagonel, V. Chop is the standard regimen in patients $>$ or $=70$ years of age with intermediate-grade and high-grade non-hodgkin's lymphoma: Results of a randomized study of the european organization for research and treatment of cancer lymphoma cooperative study group. J. Clin. Oncol. 1998, 16, 27-34. [CrossRef] [PubMed]

25. Mittal, N.K.; Bhattacharjee, H.; Mandal, B.; Balabathula, P.; Thoma, L.A.; Wood, G.C. Targeted liposomal drug delivery systems for the treatment of b cell malignancies. J. Drug Targ. 2014, 22, 372-386. [CrossRef] [PubMed] 
26. Binsky, I.; Haran, M.; Starlets, D.; Gore, Y.; Lantner, F.; Harpaz, N.; Leng, L.; Goldenberg, D.M.; Shvidel, L.; Berrebi, A.; et al. Il-8 secreted in a macrophage migration-inhibitory factor- and cd74-dependent manner regulates b cell chronic lymphocytic leukemia survival. Proc. Natl. Acad. Sci. USA 2007, 104, 13408-13413. [CrossRef] [PubMed]

27. DiJoseph, J.F.; Dougher, M.M.; Kalyandrug, L.B.; Armellino, D.C.; Boghaert, E.R.; Hamann, P.R.; Moran, J.K.; Damle, N.K. Antitumor efficacy of a combination of cmc-544 (inotuzumab ozogamicin), a cd22-targeted cytotoxic immunoconjugate of calicheamicin, and rituximab against non-hodgkin's b-cell lymphoma. Clin. Cancer Res. 2006, 12, 242-249. [CrossRef] [PubMed]

28. Du, X.; Beers, R.; Fitzgerald, D.J.; Pastan, I. Differential cellular internalization of anti-cd19 and -cd22 immunotoxins results in different cytotoxic activity. Cancer Res 2008, 68, 6300-6305. [CrossRef] [PubMed]

29. Loomis, K.; Smith, B.; Feng, Y.; Garg, H.; Yavlovich, A.; Campbell-Massa, R.; Dimitrov, D.S.; Blumenthal, R.; Xiao, X.; Puri, A. Specific targeting to b cells by lipid-based nanoparticles conjugated with a novel cd22-scfv. Exp. Mol. Pathol. 2010, 88, 238-249. [CrossRef] [PubMed]

30. Sapra, P.; Allen, T.M. Improved outcome when b-cell lymphoma is treated with combinations of immunoliposomal anticancer drugs targeted to both the cd19 and cd20 epitopes. Clin. Cancer Res. 2004, 10, 2530-2537. [CrossRef] [PubMed]

31. Tuscano, J.M.; Martin, S.M.; Ma, Y.; Zamboni, W.; O’Donnell, R.T. Efficacy, biodistribution, and pharmacokinetics of cd22-targeted pegylated liposomal doxorubicin in a b-cell non-hodgkin's lymphoma xenograft mouse model. Clin. Cancer Res. 2010, 16, 2760-2768. [CrossRef] [PubMed]

32. O’Donnell, R.T.; Martin, S.M.; Ma, Y.; Zamboni, W.C.; Tuscano, J.M. Development and characterization of cd22-targeted pegylated-liposomal doxorubicin (il-pld). Investig. New Drugs 2010, 28, 260-267. [CrossRef] [PubMed]

33. Sapra, P.; Allen, T.M. Internalizing antibodies are necessary for improved therapeutic efficacy of antibody-targeted liposomal drugs. Cancer Res. 2002, 62, 7190-7194. [PubMed]

34. Sapra, P.; Moase, E.H.; Ma, J.; Allen, T.M. Improved therapeutic responses in a xenograft model of human b lymphoma (namalwa) for liposomal vincristine versus liposomal doxorubicin targeted via anti-cd19 igg2a or fab' fragments. Clin. Cancer Res. 2004, 10, 1100-1111. [CrossRef] [PubMed]

35. Frishman, W.H.; Sung, H.M.; Yee, H.C.M.; Liu, L.L.; Einzig, A.I.; Dutcher, J.; Keefe, D. Cardiovascular toxicity with cancer chemotherapy. Curr. Probl. Cardiol. 1996, 21, 233-286. [CrossRef]

36. Jensen, B.; Skovsgaard, T.; Nielsen, S. Functional monitoring of anthracycline cardiotoxicity: A prospective, blinded, long-term observational study of outcome in 120 patients. Ann. Oncol. 2002, 13, 699-709. [CrossRef] [PubMed]

37. Speyer, J.; Wasserheit, C. Strategies for reduction of anthracycline cardiac toxicity. Semin. Oncol. 1998, 25, 525-537. [PubMed]

38. Binaschi, M.; Bigioni, M.; Cipollone, A.; Rossi, C.; Goso, C.; Maggi, C.A.; Capranico, G.; Animati, F. Anthracyclines: Selected new developments. Curr. Med. Chem. Anti-Cancer Agents 2001, 1, 113-130. [CrossRef] [PubMed]

39. Teicher, B.A. Cancer Therapeutics: Experimental and Clinical Agents; Springer Science \& Business Media: Berlin, Germany, 1996.

40. He, Y.; Liu, J.; Durrant, D.; Yang, H.S.; Sweatman, T.; Lothstein, L.; Lee, R.M. N-benzyladriamycin-14-valerate (AD198) induces apoptosis through protein kinase C-delta-induced phosphorylation of phospholipid scramblase 3. Cancer Res. 2005, 65, 10016-10023. [CrossRef] [PubMed]

41. Hofmann, P.A.; Israel, M.; Koseki, Y.; Laskin, J.; Gray, J.; Janik, A.; Sweatman, T.W.; Lothstein, L. $\mathrm{N}$-benzyladriamycin-14-valerate (AD 198): A non-cardiotoxic anthracycline that is cardioprotective through pkc-epsilon activation. J. Pharmacol. Exp. Ther. 2007, 323, 658-664. [CrossRef] [PubMed]

42. Cai, C.; Lothstein, L.; Morrison, R.R.; Hofmann, P.A. Protection from doxorubicin-induced cardiomyopathy using the modified anthracycline $N$-benzyladriamycin-14-valerate (AD 198). J. Pharmacol. Exp. Ther. 2010, 335, 223-230. [CrossRef] [PubMed]

43. Lothstein, L.; Savranskaya, L.; Barrett, C.M.; Israel, M.; Sweatman, T.W. N-benzyladriamycin-14-valerate (AD 198) activates protein kinase $\mathrm{c}-\delta$ holoenzyme to trigger mitochondrial depolarization and cytochrome $\mathrm{c}$ release independently of permeability transition pore opening and $\mathrm{Ca}^{2+}$ influx. Anti-Cancer Drugs 2006, 17, 495-502. [CrossRef] [PubMed] 
44. Rathore, K.; Cekanova, M. A novel derivative of doxorubicin, AD198, inhibits canine transitional cell carcinoma and osteosarcoma cells in vitro. Drug Des. Dev. Ther. 2015, 9, 5323-5335.

45. Edwards, S.K.; Han, Y.; Liu, Y.; Kreider, B.Z.; Liu, Y.; Grewal, S.; Desai, A.; Baron, J.; Moore, C.R.; Luo, C. Signaling mechanisms of bortezomib in traf3-deficient mouse $\mathrm{b}$ lymphoma and human multiple myeloma cells. Leuk. Res. 2016, 41, 85-95. [CrossRef] [PubMed]

46. Mittal, N.K. Design, Development, Characterization and Testing of CD22 Targeted Long Circulating Liposomal Drug Delivery Systems for $\beta$ Cell Malignancies. Ph.D. Thesis, University of Tennessee, Knoxville, TN, USA, 2015.

47. Bangham, A.; Horne, R. Negative staining of phospholipids and their structural modification by surface-active agents as observed in the electron microscope. J. Mol. Biol. 1964, 8, 660-668. [CrossRef]

48. Lopes de Menezes, D.E.; Pilarski, L.M.; Allen, T.M. In vitro and in vivo targeting of immunoliposomal doxorubicin to human b-cell lymphoma. Cancer Res. 1998, 58, 3320-3330. [PubMed]

49. Juliano, R.L.; Stamp, D. The effect of particle size and charge on the clearance rates of liposomes and liposome encapsulated drugs. Biochem. Biophys. Res. Commun. 1975, 63, 651-658. [CrossRef]

50. Haran, G.; Cohen, R.; Bar, L.K.; Barenholz, Y. Transmembrane ammonium sulfate gradients in liposomes produce efficient and stable entrapment of amphipathic weak bases. Biochim. Biophys. Acta-Biomembr. 1993, 1151, 201-215. [CrossRef]

51. Lothstein, L.; Rodrigues, P.J.; Sweatman, T.W.; Israel, M. Cytotoxicity and intracellular biotransformation of $N$-benzyladriamycin-14-yalerate (AD 198) are modulated by changes in 14-O-acyl chain length. Anti-Cancer Drugs 1998, 9, 58-66. [CrossRef] [PubMed]

52. Stewart, J.C.M. Colorimetric determination of phospholipids with ammonium ferrothiocyanate. Anal. Biochem. 1980, 104, 10-14. [CrossRef]

53. Zhang, L.; Chan, J.M.; Gu, F.X.; Rhee, J.-W.; Wang, A.Z.; Radovic-Moreno, A.F.; Alexis, F.; Langer, R.; Farokhzad, O.C. Self-assembled lipid-polymer hybrid nanoparticles: A robust drug delivery platform. ACS Nano 2008, 2, 1696-1702. [CrossRef] [PubMed]

54. Chan, J.M.; Zhang, L.; Yuet, K.P.; Liao, G.; Rhee, J.-W.; Langer, R.; Farokhzad, O.C. PLGA-lecithin-PEG core-shell nanoparticles for controlled drug delivery. Biomaterials 2009, 30, 1627-1634. [CrossRef] [PubMed]

55. Zhang, L.; Radovic-Moreno, A.F.; Alexis, F.; Gu, F.X.; Basto, P.A.; Bagalkot, V.; Jon, S.; Langer, R.S.; Farokhzad, O.C. Co-delivery of hydrophobic and hydrophilic drugs from nanoparticle-aptamer bioconjugates. ChemMedChem 2007, 2, 1268-1271. [CrossRef] [PubMed]

56. Oliveira, S.; Schiffelers, R.M.; van der Veeken, J.; van der Meel, R.; Vongpromek, R.; en Henegouwen, P.M.V.B.; Storm, G.; Roovers, R.C. Downregulation of EGFR by a novel multivalent nanobody-liposome platform. J. Control. Release 2010, 145, 165-175. [CrossRef] [PubMed]

57. Huth, U.S.; Schubert, R.; Peschka-Süss, R. Investigating the uptake and intracellular fate of pH-sensitive liposomes by flow cytometry and spectral bio-imaging. J. Control. Release 2006, 110, 490-504. [CrossRef] [PubMed]

58. Mosmann, T. Rapid colorimetric assay for cellular growth and survival: Application to proliferation and cytotoxicity assays. J. Immunol. Methods 1983, 65, 55-63. [CrossRef]

59. Douglas, K.L.; Piccirillo, C.A.; Tabrizian, M. Cell line-dependent internalization pathways and intracellular trafficking determine transfection efficiency of nanoparticle vectors. Eur. J. Pharm. Biopharm. 2008, 68, 676-687. [CrossRef] [PubMed]

60. Gao, H.; Yang, Z.; Zhang, S.; Cao, S.; Shen, S.; Pang, Z.; Jiang, X. Ligand modified nanoparticles increases cell uptake, alters endocytosis and elevates glioma distribution and internalization. Sci. Rep. 2013, 3. [CrossRef] [PubMed]

61. Suresh, D.; Zambre, A.; Chanda, N.; Hoffman, T.J.; Smith, C.J.; Robertson, J.D.; Kannan, R. Bombesin peptide conjugated gold nanocages internalize via clathrin mediated endocytosis. Bioconjug. Chem. 2014, 25, 1565-1579. [CrossRef] [PubMed]

62. Päuser, S.; Reszka, R.; Wagner, S.; Wolf, K.J.; Buhr, H.J.; Berger, G. Liposome-encapsulated superparamagnetic iron oxide particles as markers in an MRI-guided search for tumor-specific drug carriers. Anticancer Drug Des. 1997, 12, 125-135. [PubMed]

63. Wu, L.; Yu, X.; Feizpour, A.; Reinhard, B.M. Nanoconjugation: A materials approach to enhance epidermal growth factor induced apoptosis. Biomater. Sci. 2014, 2, 156-166. [CrossRef] [PubMed] 
64. Jiang, M.; Gan, L.; Zhu, C.; Dong, Y.; Liu, J.; Gan, Y. Cationic core-shell liponanoparticles for ocular gene delivery. Biomaterials 2012, 33, 7621-7630. [CrossRef] [PubMed]

65. Zhao, Z.; Lou, S.; Hu, Y.; Zhu, J.; Zhang, C. A nano-in-nano polymer-dendrimer nanoparticle-based nanosystem for controlled multidrug delivery. Mol. Pharm. 2017, 14, 2697-2710. [CrossRef] [PubMed]

66. Jaggi, M.; Rao, P.S.; Smith, D.J.; Wheelock, M.J.; Johnson, K.R.; Hemstreet, G.P.; Balaji, K. E-cadherin phosphorylation by protein kinase $\mathrm{D} 1$ / protein kinase $\mathrm{C} \mu$ is associated with altered cellular aggregation and motility in prostate cancer. Cancer Res. 2005, 65, 483-492. [PubMed]

67. Lian, T.; Ho, R.J. Trends and developments in liposome drug delivery systems. J. Pharm. Sci. 2001, 90, 667-680. [CrossRef] [PubMed]

68. Gregoriadis, G.; Senior, J. The phospholipid component of small unilamellar liposomes controls the rate of clearance of entrapped solutes from the circulation. FEBS Lett. 1980, 119, 43-46. [CrossRef]

69. Senior, J.H. Fate and behavior of liposomes in vivo: A review of controlling factors. Crit. Rev. Ther. Drug Carr. Syst. 1987, 3, 123-193.

70. Drummond, D.C.; Meyer, O.; Hong, K.; Kirpotin, D.B.; Papahadjopoulos, D. Optimizing liposomes for delivery of chemotherapeutic agents to solid tumors. Pharmacol. Rev. 1999, 51, 691-743. [PubMed]

71. Hu, Y.; Hoerle, R.; Ehrich, M.; Zhang, C. Engineering the lipid layer of lipid-PLGA hybrid nanoparticles for enhanced in vitro cellular uptake and improved stability. Acta Biomater. 2015, 28, 149-159. [CrossRef] [PubMed]

72. Woodle, M.C.; Matthay, K.K.; Newman, M.S.; Hidayat, J.E.; Collins, L.R.; Redemann, C.; Martin, F.J.; Papahadjopoulos, D. Versatility in lipid compositions showing prolonged circulation with sterically stabilized liposomes. Biochim. Biophys. Acta 1992, 1105, 193-200. [CrossRef]

73. Gramse, G.; Dols-Perez, A.; Edwards, M.A.; Fumagalli, L.; Gomila, G. Nanoscale measurement of the dielectric constant of supported lipid bilayers in aqueous solutions with electrostatic force microscopy. Biophys. J. 2013, 104, 1257-1262. [CrossRef] [PubMed]

74. Torre, L.G.; Carneiro, A.L.; Rosada, R.S.; Silva, C.L.; Santana, M.H.A. A mathematical model describing the kinetic of cationic liposome production from dried lipid films adsorbed in a multitubular system. Br. J. Chem. Eng. 2007, 24, 477-486. [CrossRef]

75. Budha, N.R.; Lee, R.B.; Hurdle, J.G.; Lee, R.E.; Meibohm, B. A simple in vitro PK/PD model system to determine time-kill curves of drugs against mycobacteria. Tuberculosis 2009, 89, 378-385. [CrossRef] [PubMed]

76. Schmid, S.L.; Carter, L.L. ATP is required for receptor-mediated endocytosis in intact cells. J. Cell Biol. 1990, 111, 2307-2318. [CrossRef] [PubMed]

77. Kou, L.; Sun, J.; Zhai, Y.; He, Z. The endocytosis and intracellular fate of nanomedicines: Implication for rational design. Asian J. Pharm. Sci. 2013, 8, 1-10. [CrossRef]

78. Luzio, J.P.; Pryor, P.R.; Bright, N.A. Lysosomes: Fusion and function. Nat. Rev. Mol. Cell Biol. 2007, 8, 622-632. [CrossRef] [PubMed]

79. Finver, S.N.; Nishikura, K.; Finger, L.R.; Haluska, F.G.; Finan, J.; Nowell, P.C.; Croce, C.M. Sequence analysis of the MYC oncogene involved in the $\mathrm{t}(8 ; 14)(\mathrm{q} 24 ; \mathrm{q} 11)$ chromosome translocation in a human leukemia T-cell line indicates that putative regulatory regions are not altered. Proc. Natl. Acad. Sci. USA 1988, 85, 3052-3056. [CrossRef] [PubMed]

80. Nicholson, K.M.; Anderson, N.G. The protein kinase B/Akt signalling pathway in human malignancy. Cell. Signal. 2002, 14, 381-395. [CrossRef]

81. Sarbassov, D.D.; Guertin, D.A.; Ali, S.M.; Sabatini, D.M. Phosphorylation and regulation of Akt/PKB by the rictor-mtor complex. Science 2005, 307, 1098-1101. [CrossRef] [PubMed]

82. Edwards, S.K.; Moore, C.R.; Liu, Y.; Grewal, S.; Covey, L.R.; Xie, P. N-benzyladriamycin-14-valerate (AD 198) exhibits potent anti-tumor activity on TRAF3-deficient mouse b lymphoma and human multiple myeloma. BMC Cancer 2013, 13, 481. [CrossRef] [PubMed]

83. Bubici, C.; Papa, S. Jnk signalling in cancer: In need of new, smarter therapeutic targets. Br. J. Pharmacol. 2014, 171, 24-37. [CrossRef] [PubMed]

(C) 2018 by the authors. Licensee MDPI, Basel, Switzerland. This article is an open access article distributed under the terms and conditions of the Creative Commons Attribution (CC BY) license (http:/ / creativecommons.org/licenses/by/4.0/). 